\title{
Microevolution from shock to adaptation revealed strategies improving ethanol tolerance and production in Thermoanaerobacter
}

Lu Lin ${ }^{1}$, Yuetong Ji', Qichao Tu², Ranran Huang ${ }^{1}$, Lin Teng ${ }^{1}$, Xiaowei Zeng ${ }^{1}$, Houhui Song ${ }^{1}$, Kun Wang ${ }^{1}$, Qian Zhou', Yifei Li', Qiu Cui ${ }^{1}$, Zhili He${ }^{2}$, Jizhong Zhou ${ }^{2}$ and Jian Xü ${ }^{1 *}$

\begin{abstract}
Introduction: The molecular links between shock-response and adaptation remain poorly understood, particularly for extremophiles. This has hindered rational engineering of solvent tolerance and correlated traits (e.g., productivity) in extremophiles. To untangle such molecular links, here we established a model that tracked the microevolution from shock to adaptation in thermophilic bacteria.

Method: Temporal dynamics of genomes and transcriptomes was tracked for Thermoanaerobacter sp. X514 which under increasing exogenous ethanol evolved from ethanol-sensitive wild-type (Strain $X)$ to tolerance of 2\%- $\left(X_{1}\right)$ and eventually $6 \%$-ethanol $\left(X_{\|}\right)$. Based on the reconstructed transcriptional network underlying stress tolerance, genetic engineering was employed to improve ethanol tolerance and production in Thermoanaerobacter.

Results: The spontaneous genome mutation rate $\left(\mu_{\mathrm{g}}\right)$ of Thermoanaerobacter sp. X514, calculated at 0.045, suggested a higher mutation rate in thermophile than previously thought. Transcriptomic comparison revealed that shock-response and adaptation were distinct in nature, whereas the transcriptomes of $X_{\|}$resembled those of the extendedly shocked $X$. To respond to ethanol shock, $X$ employed fructose-specific phosphotransferase system (PTS), Arginine Deiminase (ADI) pathway, alcohol dehydrogenase (Adh) and a distinct mechanism of V-type ATPase. As an adaptation to exogenous ethanol, $X_{1}$ mobilized resistance-nodulation-cell division (RND) efflux system and Adh, whereas $X_{I I}$, which produced higher ethanol than $X_{1}$, employed ECF-type $\sigma^{24}$, an alcohol catabolism operon and phase-specific heat-shock proteins (Hsps), modulated hexose/pentose-transport operon structure and reinforced membrane rigidity. Exploiting these findings, we further showed that ethanol productivity and tolerance can be improved simultaneously by overexpressing adh or $\sigma^{24}$ in X.

Conclusion: Our work revealed thermophilic-bacteria specific features of adaptive evolution and demonstrated a rational strategy to engineer co-evolving industrial traits. As improvements of shock-response, stress tolerance and productivity have been crucial aims in industrial applications employing thermophiles, our findings should be valuable not just to the production of ethanol but also to a wide variety of biofuels and biochemicals.
\end{abstract}

Keywords: Shock, Adaptation, Ethanol, Microevolution, Thermophile

\footnotetext{
* Correspondence: xujian@qibebt.ac.cn

${ }^{1}$ BioEnergy Genome Center, CAS Key Laboratory of Biofuels and Shandong

Key Laboratory of Energy Genetics, Qingdao Institute of Bioenergy and

Bioprocess Technology, Chinese Academy of Sciences, Qingdao, Shandong,

P. R. China

Full list of author information is available at the end of the article
} 


\section{Introduction}

Adaptive evolution is a universal theme of life on our planet [1-3]. It is also a widely practiced strategy for selecting and engineering economically valuable traits [4-6]. Adaptive evolution typically starts from an environmental change and results in genetically inheritable adaptation [3,7]. The initial cellular response, which usually includes a transient reprogramming of cellular activities, is termed "shock", while the subsequent cellular state that involves inheritable traits resulted from longterm exposure and selection (i.e., after generations) is termed "adaptation". Numerous studies have investigated the cellular programs underlying shock (e.g., Escherichia coli $[5,8,9]$; Saccharomyces cerevisiae $[10,11]$ and Clostridium acetobutylicum [12,13]) or adaptation [6,11,14-21], but few have attempted to test their links by tracking the temporal development from shockresponse to the eventual adaptation $[10,22,23]$. The vast numbers of genetic variables (e.g., strains used) and environmental variables (e.g., culture conditions) across the studies hampered meaningful comparisons between shock- and adaptation-responses. Thus the molecular links between shock and adaptation are not yet well established, and the temporal characteristics and genetic mechanisms defining the shock-to-adaptation process remain elusive $[10,11]$. Moreover, whether and how the process was shaped by ecological parameters such as temperature is largely unknown.

Although most contemporary life forms are found at a narrow range of $24-40^{\circ} \mathrm{C}$ [24], the thermophiles thrive under optimal temperature of $>50^{\circ} \mathrm{C}$ [24]. These organisms play a profound role in evolution and ecology of our biosphere (primordial life on earth is believed by many to be thermophilic [2]). They have also found wide applications in biotechnology. For example, thermophilic gram-positive anaerobes (TGPAs) such as certain Thermoanaerobacter and Clostridium species are of interest in producing solvents (e.g., ethanol, butanol and isopropanol) from lignocelluloses under a Consolidated Bioprocessing (CBP) scheme [25,26], due to their thermophilic nature $\left(60-65^{\circ} \mathrm{C}\right)$, wide spectrum of carbon-sources $[27,28]$ and co-utilization of pentose and hexose [25]. However, as is the case in many mesophiles, TGPAs are generally sensitive to excessive concentrations of their own solvent products [27], which reduce cell vitality, impair membrane integrity, inhibit enzymes and/or perturb intracellular $\mathrm{pH}$ balance $[29,30]$. Cellular tolerance to solvents can be derived by adaptive evolution of the wild-type strains via exposure to exogenous solvents for months or even years [30,31]. However, solvent-tolerant strains derived via such a strategy usually exhibit lower productivity of the solvent (although this reduction in yield was not proportional; $[4,31]$ ); this negative correlation between tolerance and productivity represents a major hurdle in strain development. In fact, although for many organisms genetic engineering of either solvent tolerance (e.g., $[4,6])$ or solvent productivity (e.g., $[25,27,32]$ ) has been accomplished, simultaneous improvement of solvent tolerance and productivity has not been demonstrated in thermophiles [4,33]. Devising a rational strategy to counter this hurdle might require a mechanistic understanding of the co-evolution of such linked traits.

Here we developed a model of adaptive evolution for thermophiles by evolving, under increasing concentrations of exogenous ethanol, a Thermoanaerobacter sp. X514 (NCBI Taxonomy ID: 399726) lineage from the ethanolsensitive wild-type to tolerance of $2 \%$ ethanol, and eventually to $6 \%$-ethanol tolerance. The genomes, transcriptomes and gene networks were traced and compared on a temporal scale, which unveiled the molecular links between shock and adaptation and revealed unusual features of "thermophilic" adaptive evolution. Furthermore, these findings enabled us to demonstrate that for wild-type TGPA strains, the two linked and co-evolving traits of ethanol productivity and ethanol tolerance could be simultaneously improved by genetic approaches (overexpressing an iron-containing Adh enzyme (Teth5140145-0146) or an ECF subfamily RNA polymerase sigma-24 factor regulator $\left(6^{24}\right.$, Teth5141847-1848)).

\section{Results}

An experimental model of adaptive evolution from shock to adaptation in thermophilic bacteria

Thermoanaerobacter sp. X514 is a TGPA we previously used for dissecting the mechanism of pentose-hexose coutilization [25] and ethanol production [34]. We first designed a trackable experimental model of adaptive evolution for thermophiles (Figure 1A and 1B) by exploiting the observed ethanol-sensitivity of wild-type X514 (designated "X"; Additional file 1A) to the mutant strain $X_{I}$ ("low ethanol tolerance", i.e., tolerating $2 \%$ ethanol; Additional file 2A; Methods) that was one isolate of Xp (a mixed culture of mutants that were developed from $\mathrm{X}$ via sequential transfer) and eventually to another mutant strain $\mathrm{X}_{\mathrm{II}}$ ("high-ethanol tolerance", i.e., tolerating 6\% ethanol; Additional file 2A; Methods). The three developmental phases of ethanol tolerances represented by $\mathrm{X}, \mathrm{X}_{\mathrm{I}}$ (and $\mathrm{Xp}$ ) and $\mathrm{X}_{\mathrm{II}}$ were interrogated under three "Views" (Figure 1A): (i) Phenotypic adaptation (in $\mathrm{X}, \mathrm{X}_{\mathrm{I}}$ and $\mathrm{X}_{\mathrm{II}}$ ) (View I; Additional file 2). (ii) Transcriptomic responses that respectively defined four time-points under ethanol shock and the two phases of ethanol adaptation (View II; Figures 2 and Figure 3). Under the particular culture medium, the ethanol concentration that caused stress but not significant cell death in $\mathrm{X}$ was $0.15 \%(\mathrm{v} / \mathrm{v})$, which was selected for the ethanol shock assay (Additional file 1A). Thus, subsequent shock responses were examined by comparing $\mathrm{X}-0.15 \%$ (X cells cultured at defined medium 


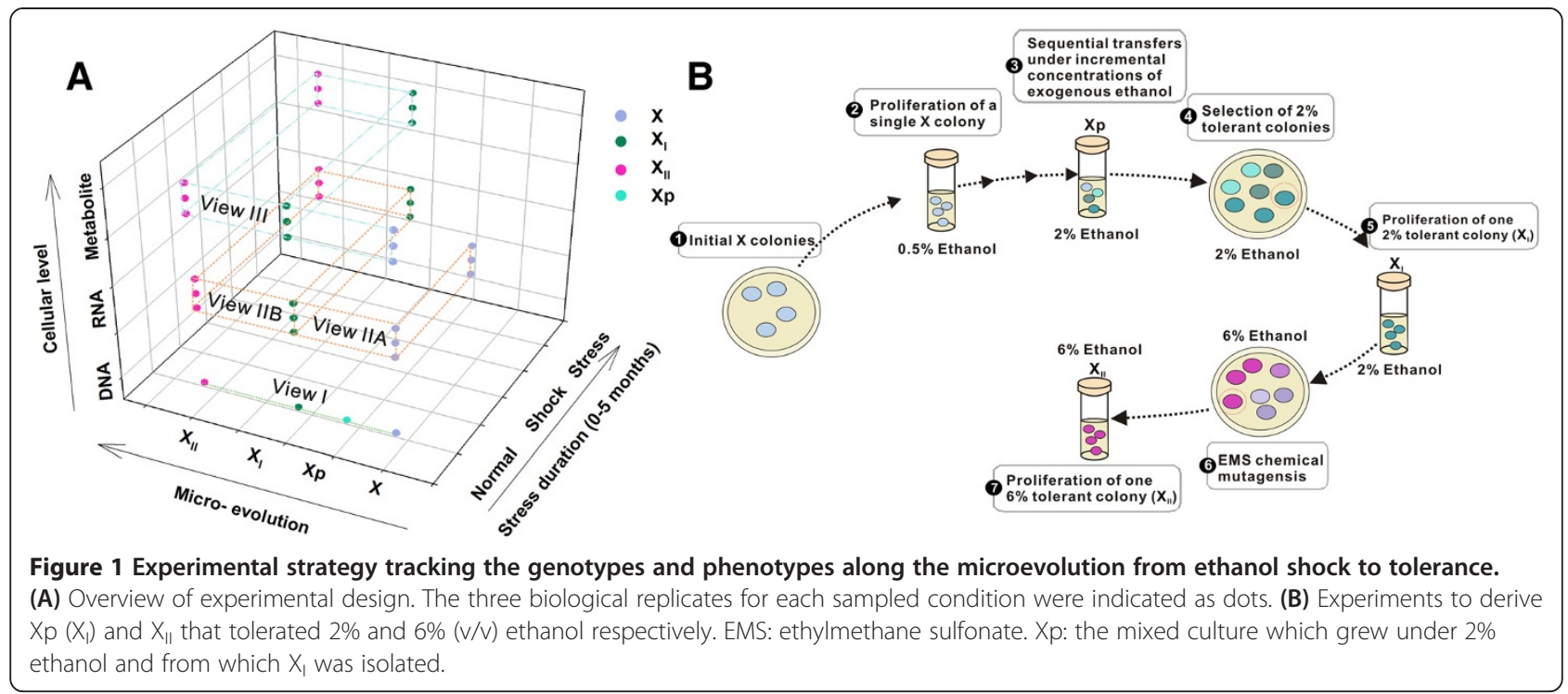

with $0.15 \%$ exogenous ethanol; View IIA) to X-0\% (X cells cultured without exogenous ethanol); moreover, dynamics of shock responses was tested by sampling $\mathrm{X}$ transcriptomes at four time points $(0.5 \mathrm{~h}, 1 \mathrm{~h}, 2 \mathrm{~h}$ and $4 \mathrm{~h})$ upon ethanol exposure. On the other hand, mechanism of ethanol tolerance was revealed by the transcriptomes of $X_{I}$ $\left(\mathrm{X}_{\mathrm{I}}-0 \%\right.$ and $\mathrm{X}_{\mathrm{I}}-2 \% ; \mathrm{X}_{\mathrm{I}}$ cells cultured under $0 \%$ and $2 \%$ ethanol respectively) and those of $\mathrm{X}_{\mathrm{II}}\left(\mathrm{X}_{\mathrm{II}}-0 \%\right.$ and $\mathrm{X}_{\mathrm{II}}-6 \%$; $\mathrm{X}_{\mathrm{II}}$ cells cultured under $0 \%$ and $6 \%$ ethanol respectively; View IIB). In addition to microarray-based expression profiling, RNA-Seq was employed so as to detect all structural and sequence changes of transcripts during the microevolution. (iii) Genome sequence mutations (for $\mathrm{X}, \mathrm{Xp}, \mathrm{X}_{\mathrm{I}}$ and $\mathrm{X}_{\mathrm{II}}$ ) (View III; Figure 2). To precisely identify every

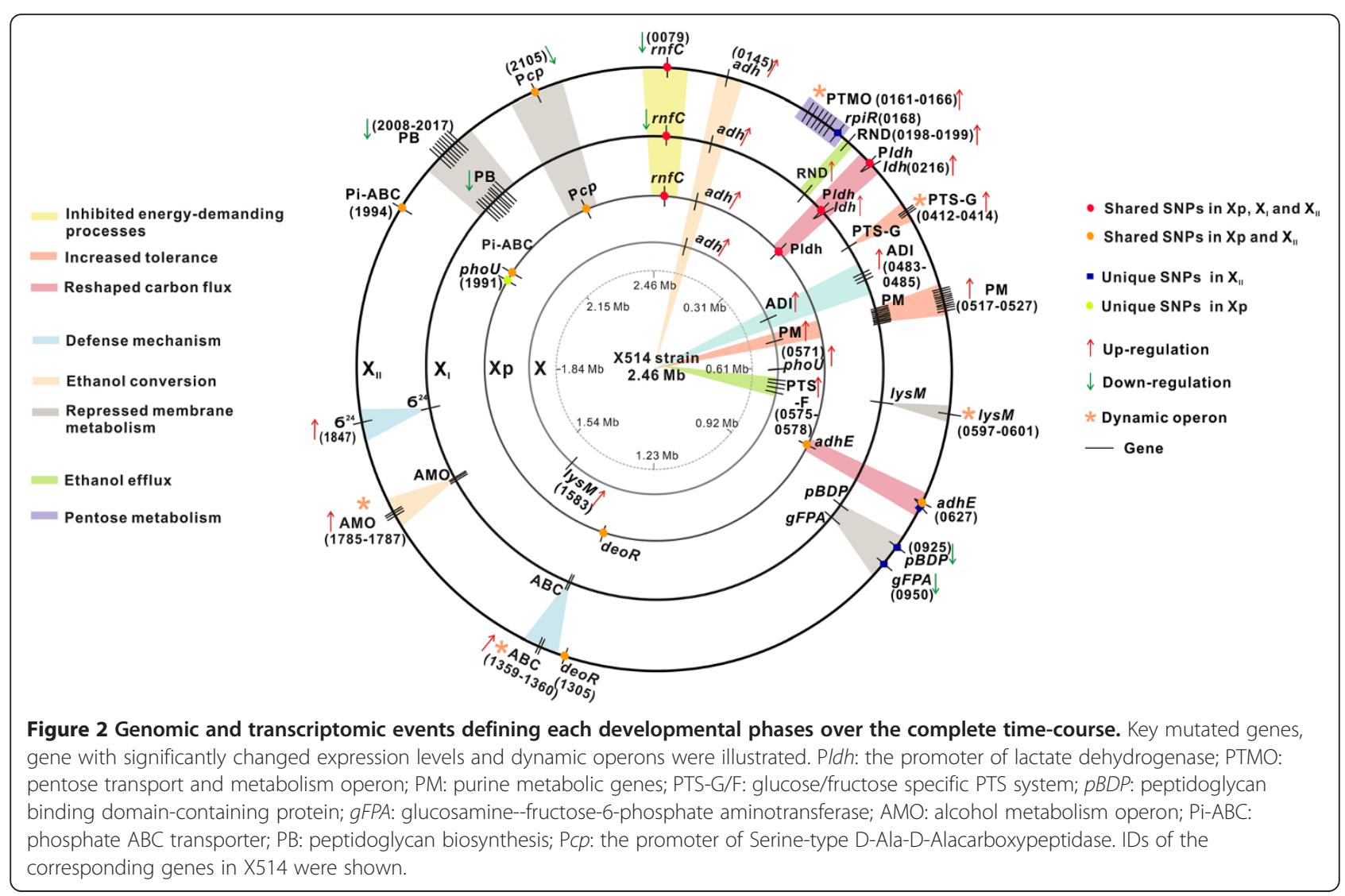




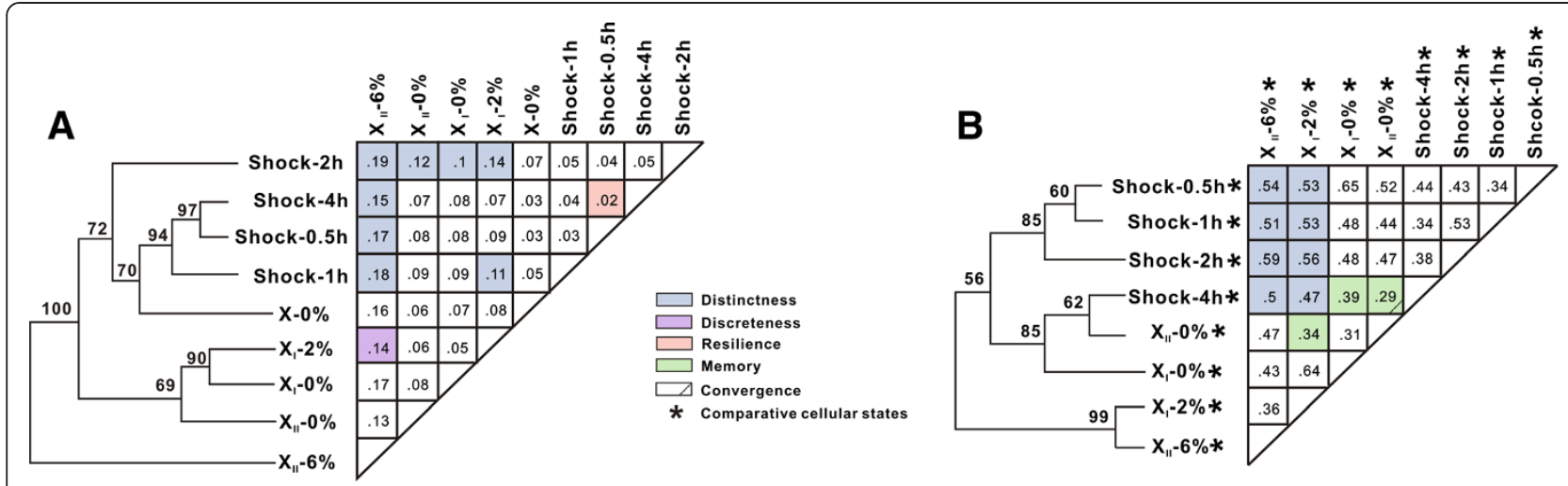

Figure 3 Links among the cellular states of shock and tolerance as defined by transcriptome. (A) Links among the nine cellular states. (B) Links among the eight relative cellular states. The number in each square represented the distance between each pair-wise comparison as calculated based on Pearson Correlation. Hierarchical clustering of the nine cellular states and the eight relative cellular states were shown respectively. Numbers on the branches represent bootstrap values as percentages of 1000 resampling efforts of the dataset. The clustering analysis was performed by TM4 software [57].

genotypic change along the microevolution, we resequenced the $\mathrm{X}, \mathrm{X}_{\mathrm{I}}$ and $\mathrm{X}_{\mathrm{II}}$ genomes and the metagenome of $\mathrm{Xp}$, using the previously finished wild-type $\mathrm{X} 514$ genome [34] as reference.

Higher concentrations of exogenous ethanol slowed down growth in all strains (Additional file 2A), with reduction in cell length correlated with improvements in tolerance (Additional file 3). Glycolysis in the tolerant mutants was as robust as that in the wild-type yet the carbohydrate metabolism was altered, as in the absence of exogenous ethanol, $\mathrm{X}_{\mathrm{I}}$ and $\mathrm{X}_{\mathrm{II}}$ consumed more glucose (100:120:115 for $\mathrm{X}$ : $\left.\mathrm{X}_{\mathrm{I}}: \mathrm{X}_{\mathrm{II}}\right)$ yet produced less ethanol (100:45:70 for X: $\mathrm{X}_{\mathrm{I}}: \mathrm{X}_{\mathrm{II}}$ ) than X (Additional file 2B).

In $\mathrm{Xp}, \mathrm{X}_{\mathrm{I}}$ and $\mathrm{X}_{\mathrm{II}}$ genomes (in reference to $\mathrm{X}$; Methods), 76 (74 single-nucleotide polymorphisms (SNPs) and two single-base indels), 20 (19 SNPs and one single-base indel) and 45 (43 SNPs and two single-base indels) mutations were respectively found (Figure 2; Additional file 4). Along the microevolution, the ratio between non-coding sequence mutations and those in coding sequence stayed largely unchanged (from $17.6 \%$ in $\mathrm{X}_{\mathrm{I}}$ to $15.4 \%$ in $\mathrm{X}_{\mathrm{II}}$ ); moreover the functional profile of non-synonymous mutations shifted from regulatory functions to structural proteins (e.g., membrane and sugar phosphate metabolisms; Additional file 4). On the other hand, in $\mathrm{X}, \mathrm{X}_{\mathrm{I}}$ and $\mathrm{X}_{\mathrm{II}}$ transcriptomes, expression-altered genes were mostly concentrated in amino acid metabolism, cell motility, coenzyme metabolism, carbohydrate metabolism and energy production (Additional file 5). Along the microevolution, the functional profile of expression-altered genes shifted from one mainly featuring amino acid metabolism and cell motility to one primarily of energy production, suggesting ethanol adaptation but not shock compromised energy generation. Together, the microevolution featured decreasing numbers of expression-altered genes (314 genes under $\mathrm{X}_{\mathrm{I}^{-}}$ $0 \%$ vs $\mathrm{X}-0 \%$ and 189 genes under $\mathrm{X}_{\mathrm{II}}-0 \%$ vs $\mathrm{X}-0 \%$ were significantly changed) yet increasing numbers of DNAsequence changes (20 mutations in $\mathrm{X}_{\mathrm{I}}$ and 45 in $\mathrm{X}_{\mathrm{II}}$ ), suggesting a temporal shift from changes in gene expression to changes in genome sequence (Figure 2, Additional file 5 and Additional file 4). Interestingly, expression alteration and DNA-sequence changes exhibited complementary functional landscapes. In $\mathrm{X}_{\mathrm{I}}$, the former were mainly found in amino acid, coenzyme and carbohydrate metabolisms, yet the latter mainly involved regulatory functions (transcription factors (TFs) and cis-regulatory elements) (Figure 2 and Additional file 5). In $\mathrm{X}_{\mathrm{II}}$, expression alteration mainly involved carbohydrate metabolism, energy production and amino acid metabolism, while DNAsequence changes mainly involved membrane and sugar phosphate metabolism genes and TFs (Figure 2 and Additional file 5).

Comparison between $\mathrm{X}_{\mathrm{I}}$ and $\mathrm{X}$ genomes revealed a spontaneous mutation rate per genome per generation $\left(\mu_{\mathrm{g}}\right)$ of 0.045 given 440 generations. For another thermophile Thermusthermophilus, under its optimal growth condition, a $\mu_{\mathrm{g}}$ of 0.00093 was proposed based on mutation reporter gene pyrEF [35], which was nearly 10 -fold lower than the mesophile E.coli (0.0048); the much lower $\mu_{\mathrm{g}}$ in thermophiles (mean $\mu_{\mathrm{g}} 0.00079$, range 1.4-fold) than mesophiles (mean $\mu_{\mathrm{g}} 0.0040$, range 2.9 -fold) was interpreted as due to the rapid accumulation of deleterious mutations at a temperature only $5-10^{\circ} \mathrm{C}$ higher [35]. However, under ethanol stress, our experimentally estimated $\mu_{\mathrm{g}}$ of 0.045 for X514 appeared to be two orders of magnitude higher than that of optimal-growth Thermusthermophilus and actually slightly higher than that of E.coli under isobutanol stress (0.026) [5], contradicting with the current notion [35]. 


\section{Relationship among transcriptomic programs that respectively underlie shock, low-tolerance and high- tolerance}

Relationship among the four shock-stages (X-0.15\% at $0.5 \mathrm{~h}, 1 \mathrm{~h}, 2 \mathrm{~h}$ and $4 \mathrm{~h}$ upon exogenous-ethanol exposure) and the four adaptation states $\left(\mathrm{X}_{\mathrm{I}}-0 \%, \mathrm{X}_{\mathrm{I}}-2 \%, \mathrm{X}_{\mathrm{II}}-0 \%\right.$ and $\mathrm{X}_{\mathrm{II}}-6 \%$ ) were unveiled by pair-wisely comparing the nine transcriptomic states (including X-0\%; each state in biological triplicates; Figure 3A; Methods). Three observations were apparent. (i) Shock-response and adaptation were distinct in nature (i.e., "Distinctness"), as mutant states $\left(\mathrm{X}_{\mathrm{I}}\right.$ and $\left.\mathrm{X}_{\mathrm{II}}\right)$ and $\mathrm{X}$ states formed two separate clusters, with large pairwise distances between them (mostly over 0.1). (ii) Adaptation was phased (i.e., "Discreteness"), as $\mathrm{X}_{\mathrm{II}}-6 \%$ formed an independent clad with a large pairwise distance $(0.14)$ between $\mathrm{X}_{\mathrm{II}}-6 \%$ and $\mathrm{X}_{\mathrm{I}^{-}}$ $2 \%$. (iii) For both shock-response and adaptation, their temporal development exhibited a certain degree of "Resilience". From the onset of environmental change, the transcriptomes were first altered to a distinct state but then returned to one that was closer to the original state (Figure 3A, Additional file $1 \mathrm{~B}$ and Additional file 5): for example, in shock, $\mathrm{X}-4 \mathrm{~h}$ was closer than both $\mathrm{X}-1 \mathrm{~h}$ and $\mathrm{X}-2 \mathrm{~h}$ to $\mathrm{X}-0.5 \mathrm{~h}$; similarly, in adaptation, $\mathrm{X}_{\mathrm{II}}-0 \%$ was closer to $\mathrm{X}-0 \%$ than $\mathrm{X}_{\mathrm{I}}-0 \%$.

Furthermore, to distinguish between environmental and genetic effects, the relative transcriptomic changes that included the six "normalized" transcriptomes due to environmental perturbation (X-0.15\% vs X- $0 \%$ at each of $0.5 \mathrm{~h}$, $1 \mathrm{~h}, 2 \mathrm{~h}$ and $4 \mathrm{~h} ; \mathrm{X}_{\mathrm{I}}-2 \%$ vs $\mathrm{X}_{\mathrm{I}}-0 \%$; $\mathrm{X}_{\mathrm{II}}-6 \%$ vs $\left.\mathrm{X}_{\mathrm{II}}-0 \%\right)$ and the other two caused by genetic changes $\left(X_{I}-0 \%\right.$ vs $X-0 \%$; $\mathrm{X}_{\mathrm{II}}-0 \%$ vs $\mathrm{X}-0 \%$ ) were pair-wisely compared (Figure 3B; Methods). Two findings emerged. (i) Changes of the cellular states corresponding to the evolving tolerance exhibited a degree of "Memory" left by a priori exposure to the stimuli, as demonstrated by $a$ ) the similarity between $\mathrm{X}_{\mathrm{I}}-0 \%$ (vs X-0\%) and $\mathrm{X}-0.15 \%-4 \mathrm{~h}$ (vs X-0\%-4h), and $b$ ) the similarity between $\mathrm{X}_{\mathrm{II}^{-}}-0 \%$ (vs $\mathrm{X}-0 \%$ ) and $\mathrm{X}_{\mathrm{I}}-2 \%$ (vs $\mathrm{X}_{\mathrm{I}}-0 \%$ ) (Figure 3B). (ii) The shock and adaptation programs appeared progressing towards a shared destiny of cellular state, as the shortest pair-wise distance (at 0.296) among the 28 such distances was actually found between the high-tolerance stage $\left(\mathrm{X}_{\mathrm{II}}-0 \%\right.$ (vs $\left.\left.\mathrm{X}-0 \%\right)\right)$ and the wild-type under the most extended shock (X-0.15\%-4h (vs X-0\%$4 \mathrm{~h})$ ) (Figure 3B). This suggested "Convergence", where the high-tolerance cells, in the absence of stimuli, retained certain transcriptomic features of those under extended shock.

\section{A dynamic yet coordinated response to ethanol shock (View IIA) \\ Ethanol-shock networks}

How gene networks of thermophiles respond to environmental stimuli has been poorly understood [36]. For X, two genome-wide gene co-expression networks respectively characterizing ethanol-shock cells $\left(\mathrm{ES}^{+}\right)$and control cells $\left(E S^{-}\right)$were constructed via co-expression analysis and then compared (Methods; Additional file 6). $\mathrm{ES}^{+}$ (216 nodes; 45 of them were hypothetical proteins representing new components of ethanol-shock response; Part I of Additional file 7; Additional file 6) was 23.7\% smaller than $\mathrm{ES}^{-}$(283 nodes), with eleven modules each of at least five nodes found in each network (module sizes vary substantially both within and between networks, ranging from 5 to 93 nodes). There were $30 \mathrm{ES}^{+}-$ specific (e.g., small multi-drug export, channel protein, cell wall hydrolase and ethanolamine utilization protein EutN) and $97 \mathrm{ES}^{-}$-specific nodes (electron complex and ribosomal proteins), suggesting repression of energy metabolism and protein translation and activation of detoxification under shock.

Moreover, for the 186 nodes shared between $\mathrm{ES}^{+}$and $\mathrm{ES}^{-}$, inter-node relationships were distinct. Among the top twenty such nodes with the most connections in $\mathrm{ES}^{+}$, several were known to play pivotal roles in ethanol shock. The first group was V-type ATPase, which maintains intracellular $\mathrm{pH}$ homeostasis in $S$. cerevisiae upon ethanol shock [11]. In ES ${ }^{-}$, these genes (Teth5142363-2365 and Teth5142368-2369) constituted a module (Module 10) free of inter-module links (Figure 4A and Additional file 6; also observed in our recently reported Thermoanaerobacter glycobiome network [25]). However, in $\mathrm{ES}^{+}$, these genes became connected with other genes; not only were they found in the largest module (Module 1; with 59 nodes) (Additional file 6), but also directly linked to genes protecting cells from organic solvent damages or related to membrane structure (Figure 4B; Part I of Additional file 7).

The second group consisted of genes that metabolize or exclude toxic compounds. In ES ${ }^{-}$, Module 11 (5 genes) was free of connections with other modules, indicating these five genes (aldehyde dehydrogenase (Teth5141942, aldh), microcompartment proteins (Teth5141954-1955) and dehydratases (Teth5141952-1953) (Figure 4C and Additional file 6) formed a single functional unit to metabolize toxic intermediates [37]. Interestingly, in $\mathrm{ES}^{+}$, the unit expanded to include 25 genes organized into two modules (Module 4 and 6) (Figure 4D and Additional file 6): Aldh converts acetaldehyde (the toxic product of ethanol oxidation) to acetate; Teth5142404 participates in vitamin $B_{12}$ synthesis; Teth5141943 (ATP-cobalaminadenosyltransferase; converting $\mathrm{B}_{12}$ to coenzyme $\mathrm{B}_{12}$ ) provides the essential coenzyme to $\mathrm{B}_{12}$-dependent microcompartment protein (Teth5141944); the latter and additional such proteins (Teth5141954-1955) remove extra aldehyde through major intrinsic protein (MIP) channel (Teth5141940); multi-drug exporter (Teth5142254) excludes toxic chemicals; peptidase S51 (Teth5142319) degrades misfolded proteins and prevents their accumulation. Several (Teth5141940, 


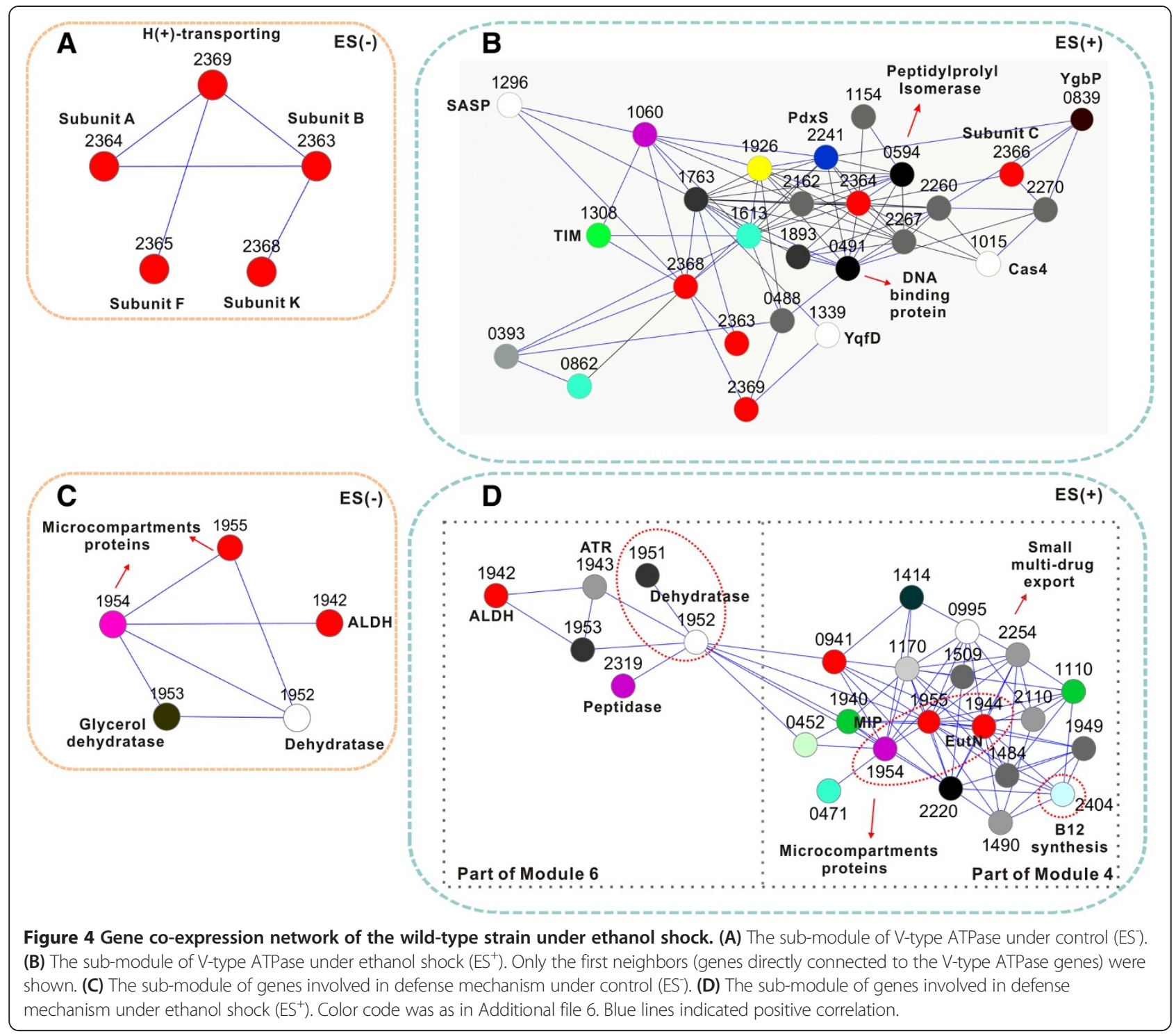

Teth5141943-1944 and Teth5142254) of these genes were absent in $\mathrm{ES}^{-}$.

\section{Dynamics of ethanol-shock networks}

Transcriptomes respectively sampled at $0.5 \mathrm{~h}, 1 \mathrm{~h}, 2 \mathrm{~h}$ and $4 \mathrm{~h}$ upon ethanol-shock revealed a total of 520 genes differentially expressed (X-0.15\% vs X-0\%) in at least one time-point ( $\left|\log _{2} R\right| \geq 1$; Additional file 8). Their expression patterns formed ten temporal clusters (Additional file 9) that include both stimulatory and inhibitory responses. An iron-containing $a d h$ (Teth5140145; one of the nine $a d h$ genes in X514 genome) and ADI Pathway (Cluster 9) $[25,38]$ were the earliest tide, peaking at $0.5 \mathrm{~h}$ and then quickly subduing. The second (Cluster 7) surged at $1 \mathrm{~h}$, among which was the small acid-soluble spore protein gene (Teth5141739) that protects DNA backbone from chemical and enzymatic cleavage. The third (Cluster 3) was induced at $2 \mathrm{~h}$ and included lys $M$ (Teth5141583) which encodes a general peptidoglycan binding function and resists ethanol damage [39]. Cluster 1, consisting of purine metabolism, fatty acid metabolism and fructose PTS genes, maintained upregulation within $2 \mathrm{~h}$. On the other hand, several clusters were downregulated. Amino acid metabolism genes (valine, arginine and tyrosine; Cluster 2) represented the earliest inhibited genes (from $0.5 \mathrm{~h}$ to $4 \mathrm{~h}$ ), followed by histidine metabolism and carbohydrate transport regulators (Cluster 5; inhibited from $1 \mathrm{~h}$ to 4 h). Subsequently, dipeptide transport, ion transport, carbohydrate transport and flagella synthesis fell during $2 \mathrm{~h}$ to $4 \mathrm{~h}$ (Clusters 4 and 6; although Cluster 4 later restored to the control level), followed by ribosomal proteins, DNA replication and carbohydrate metabolism genes (Clusters 8 and 10) that were repressed at $4 \mathrm{~h}$. Prolonged ethanol exposure extending from $0.5 \mathrm{~h}$ to $4 \mathrm{~h}$ 
resulted in dramatic increase of downregulated genes (from 37 to 350 genes; $14.1 \%$ of genome) and decrease of upregulated genes (from 40 to 4 genes) (Additional file 1B).

Therefore, upon ethanol shock, X mobilized a highly dynamic yet coordinated program organized in ten temporal clusters and involved dozens of upregulated genes (Additional file 9), however it was not clear whether any among them contributed to ethanol tolerance. Thus we next examined the $2 \%$ - and $6 \%$-ethanol-tolerant mutants.

\section{Adaptation strategy of the low-tolerance mutant Genome mutations in $X_{I}$ and $X p$}

Mutations can be beneficial, neutral or deleterious [1]. In $\mathrm{X}_{\mathrm{I}}, 20$ SNPs were identified that included 17 SNPs (6 nonsense and 11 missense) in coding and 3 in noncoding sequences (Additional file 4). Among them, six SNPs in coding regions were synonymous and thus likely neutral. To distinguish beneficial SNPs in $\mathrm{X}_{\mathrm{I}}$, we sequenced the metagenome of $\mathrm{Xp}$ to a depth equivalent to 140 sequence coverage of X514 genome, the pool of mutants that tolerated $2 \%$ ethanol, reasoning that nonsynonymous mutations with higher mutation frequency (percentage of mutated reads to all reads at a single-base locus in the X514 mutant community) were more beneficial (Additional file 10B).

Three such $\mathrm{X}_{\mathrm{I}}$-mutations were present in Xp (Part II of Additional file 7) with high frequency (>80\%), implicating energy conversion (COG C, electron transport complex I (Teth5140079) and lactate dehydrogenase (Ldh, Teth5140216)) and ion transport process (COG P, TrkH family potassium uptake protein (Teth5140140)) (Figure 2, Additional file 10C, Additional file 11 and Additional file 12; Part II of Additional file 7). Among them, one insertion mutation was found between the 10 box and the -35 box of the predicted promoter of an $l d h$ (Teth5140216) that catalyzes lactate formation (Figure 2 and Additional file 11). The distance (but not the sequence) between these two conserved elements is crucial for regulating gene expression [40]; thus this regulatory adaptation likely led to $l d h$ upregulation which was consistent with the increased $l d h$ expression level (Figure 2) and then elevated lactate production in $\mathrm{X}_{\mathrm{I}}$ (Additional file 2B).

\section{A priori ethanol stress reshaped gene network of the cell}

Comparison between $\mathrm{X}_{\mathrm{I}}-0 \%$ and $\mathrm{X}-0 \%$ revealed that $a$ priori long-term ethanol exposure reshaped metabolisms, even in the absence of exogenous ethanol (Additional file 13A and Additional file 14B). First, central carbon metabolisms were transcriptionally altered. Corresponding to the one insertion mutation in promoter, one $l d h$ (Teth5140216; the only ldh in X514 genome) was induced, whereas solvent formation genes were inhibited that included butyrate kinase (Teth5140936), phosphate butyryltransferase (Teth5140937), and iron-containing adh and its associated NADH oxidase (Teth51401450146) (Additional file 15A). In addition, several glycolysis and pentose phosphate pathway (PPP) genes (Teth5140161, Teth5140163-0165, Teth5140575-0576 and Teth5141896; Additional file 15A) were induced. Thus glycolysis in tolerant mutants was robust with carbon flux shifting from ethanol- to lactate-deriving, explaining the increased glucose consumption and elevated lactate production (Additional file 2B). Second, additional solvent formation genes were suppressed in mutants. For example, $\mathrm{B}_{12}$ dependent euts (Teth5141943-1946), whose expression level positively correlates with ethanol production in $X$ [25], were downregulated in $X_{I}$, likely contributing to the decrease in ethanol titer (Additional file 2B). Third, coenzyme $B$ metabolism was either up- $\left(B_{1}, B_{2}\right.$ and $\left.B_{5}\right)$ or down-regulated $\left(\mathrm{B}_{12}\right.$; Additional file $\left.15 \mathrm{~A}\right)$. $\mathrm{B}_{12}$ biosynthesis (Teth5140298-0320) and related cobalt transporters (Teth5141931-1934 and Teth5140297-0326), which provide coenzyme $B_{12}$ to ethanol formation genes [25], were all downregulated, leading to the lower ethanol production (Part III of Additional file 7). Fourth, genes in several stress-response pathways $[10,41]$ were upregulated in $\mathrm{X}_{\mathrm{I}}$ (Part III of Additional file 7). Among them was up-regulation of NAD/NADP octopine dehydrogenase (Teth5142108; Additional file 15A). This multifunctional enzyme catalyzed the reversible reductive condensation of arginine and pyruvic acid to Doctopine [42]. The arginine can protect cells against ethanol damage [25]. On the other hand, the octopine dehydrogenase activity was significantly correlated with the ability to buffer the acidic end products of anaerobic metabolism in the marine invertebrate cephalopods [42]. As more lactate acid was produced in $\mathrm{X}_{\mathrm{I}}$ (Additional file $2 \mathrm{~B}$ ), higher activity of this gene probably led to acid-damage resistance. Finally, nitrogen metabolism and cell wall/membrane metabolism were perturbed in $\mathrm{X}_{\mathrm{I}}$ (Part III of Additional file 7).

\section{Long-term ethanol stress changed the cellular stress- response program}

Comparison between $\mathrm{X}_{\mathrm{I}}-2 \%$ and $\mathrm{X}_{\mathrm{I}}-0 \%$ revealed how long-term stress altered the stress-response program (View IIB; Figure 5B and Additional file 14A). Overall, $\mathrm{X}_{\mathrm{I}}-2 \%$ featured an inhibited metabolism, including carbon metabolism (PPP pathways), energy conversion (e.g., acetate kinase $(a k), a d h$, and 3-isopropylmalate dehydrogenase (ipmdh)), cell membrane metabolism, DNA metabolism, coenzyme biosynthesis $\left(\mathrm{B}_{1}, \mathrm{~B}_{2}\right.$, and $\left.\mathrm{B}_{12}\right)$, amino acid synthesis and cell motility (Additional file 16A). However, several genes were upregulated. (i) Extracellular solute-binding protein and binding-protein-dependent transport systems inner membrane component in COG G (Teth5142194-2202, Teth5140534 and Teth5141044) were 


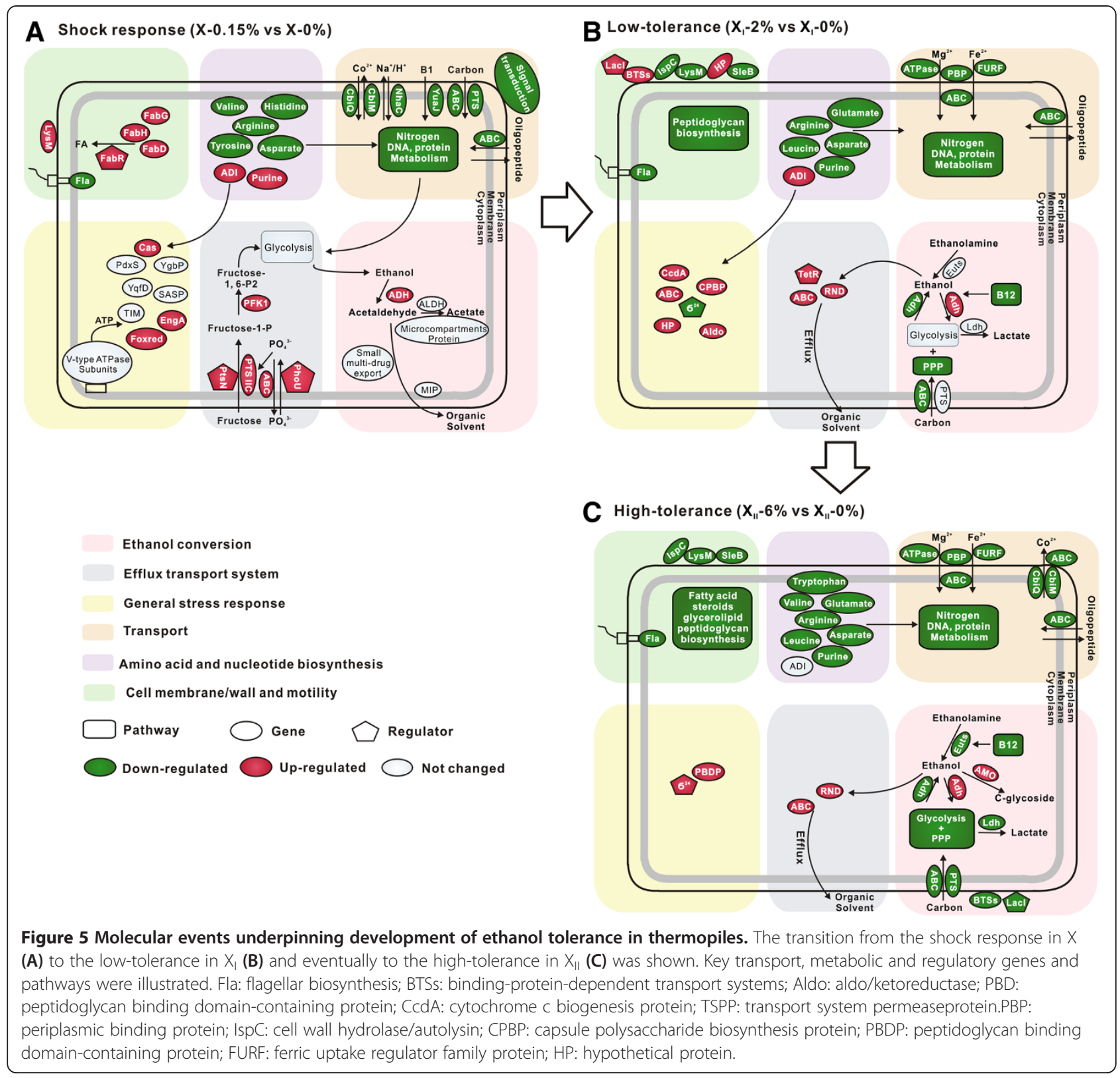

upregulated (Figure 5B and Additional file 14A), however the associated carbohydrate transport systems were not induced, suggesting changed cell surface interactions but not increased carbohydrate transports. (ii) Efflux systems were elevated that likely removed intracellular ethanol, including tetracycline repressor (TetR) family transcription factor [43], RND family efflux transporter [44] and capsule polysaccharide biosynthesis [45] (Additional file 16A). (iii) An iron-containing $a d h$ (Teth5140145) and the ADI pathway (Teth5140483-0485) were activated.

Therefore in both $\mathrm{X}$ and $\mathrm{X}_{\mathrm{I}}$, ethanol inhibited carbohydrate, amino acid and flagellar synthesis. The defense mechanisms shared between shock and low-tolerance included the $a d h$ operon that controls intracellular ethanol
[25] and ADI pathway that maintains $\mathrm{pH}$ balance $[25,38]$. On the other hand, $\mathrm{X}$ appeared to employ fructose-specific PTS systems for extruding ethanol [46], whereas $X_{I}$ mobilized RND and TetR presumably to activate efflux pumps for ethanol [43] and extracellular solute-binding protein to tune cell-surface interactions (Figure 2, Figure 5A-B and Additional file 14A).

\section{Adaptation strategy of the high-tolerance mutant Genome mutations in $X_{I I}$}

The three apparently beneficial mutations of $X_{\mathrm{I}}$, found at electron transport complex I, $l d h$ promoter and TrkH family potassium uptake protein respectively, were also found in $\mathrm{X}_{\mathrm{II}}$ (Figure 2 and Additional file 10D), consistent 
with $\mathrm{X}_{\mathrm{II}}$ being derived from $\mathrm{X}_{\mathrm{I}}$. Moreover, $12.1 \%$ of nonsynonymous mutations in $\mathrm{X}_{\mathrm{II}}$ were found in $\mathrm{Xp}$ but not in $\mathrm{X}_{\mathrm{I}}$, indicating these mutations might further enhance ethanol tolerance (Figure 2 and Additional file 10D; Part IV of Additional file 7). In both $\mathrm{Xp}$ and $\mathrm{X}_{\mathrm{II}}$, Leu ${ }^{598} \rightarrow$ Gln was found in the Fe-ADH domain of AdhE (bifunctional aldehyde/alcohol dehydrogenase; Additional file 17B). Furthermore, in $\mathrm{X}_{\mathrm{II}}$, one more SNP (His ${ }^{748} \rightarrow$ Arg) was identified in this domain (near the active-site iron and the cofactorbinding sites), likely altering the interaction between the ADH-domain and NADP (Additional file 17B; Methods) [4]. In addition, in $\mathrm{X}_{\mathrm{II}}$, analogous to the mutated $\operatorname{Rod} \mathrm{A}$ (Teth5142127) in Xp, another rod shape-determining protein, MreC, was mutated ( $\mathrm{Val}^{\mathbf{1 3 2}} \rightarrow$ Gly, Teth5142133). MreC plays a role in determining cell shape (e.g., the rodshape in E. coli [47]), likely underlying the shortened length of $\mathrm{X}_{\mathrm{II}}$ cells (Additional file 3 ).

$\mathrm{X}_{\mathrm{II}}$ harbored additional SNPs that were absent in both $\mathrm{Xp}$ and $\mathrm{X}_{\mathrm{I}}$. They were mostly in two categories: ribose metabolism (e.g., $\mathrm{Thr}^{\mathbf{9 4}} \rightarrow \mathrm{Ala}$ in RpiR) and cell membrane metabolism (Figure 2 and Additional file 10C; Part IV of Additional file 7). Thus the altered ribose and membrane metabolism in $\mathrm{X}_{\mathrm{II}}$ might contribute to the enhanced tolerance.

\section{Features of the cellular state of $X_{I I}$}

Transcriptomic comparison of $\mathrm{X}_{\mathrm{II}}-0 \%$ versus $\mathrm{X}-0 \%$ revealed characteristics of $\mathrm{X}_{\mathrm{II}}$ state, including altered carbon-metabolisms (inhibited $a d h$ cluster (Teth51401450146) in glycolysis and induced oxaloacetate decarboxylase (oad, Teth5141582; converting oxaloacetate into pyruvate)) in pyruvate metabolism, induced stress response, repressed nitrogen metabolism and inhibited cell wall/ membrane metabolism (Additional file 13B and Additional file 18; Part IV of Additional file 7). Notably, fabR (Teth5141728), a global regulator of membrane lipid biosynthesis in many Gram-positive bacteria [48], was upregulated in $\mathrm{X}_{\mathrm{II}}-0 \%$, together with teth5141723-1727. FabG (Teth5141723) and fabD (Teth5141724) were involved in long chain fatty acid biosynthesis, whereas $\mathrm{fabH}$ (Teth5141726) was the determining factor in branchedchain fatty acid biosynthesis [49]. Therefore, $\mathrm{X}_{\mathrm{II}}$ reinforced membrane rigidity against ethanol damage [30]. Such expression patterns were also observed under ethanol shock in $\mathrm{X}$ at $1 \mathrm{~h}$ and $2 \mathrm{~h}$, revealing a link between shock response and adaptation that likely underlay the observed "Memory" effect in this adaptive evolution (Figure 3B). In addition, the induction of heat shock proteins (Hsps, which were a universal response to ethanol stress in mesophiles) was not observed under either the shock to $\mathrm{X}(\mathrm{X}-0.15 \%$ vs $\mathrm{X}-0 \%)$ or the stress to the mutants $\left(X_{I}-2 \%\right.$ vs $X_{I}-0 \%$ and $X_{I I}-6 \%$ vs $\left.X_{I I}-0 \%\right)$ (Part V of Additional file 7), suggesting one TGPAspecific feature of adaptive evolution.

\section{Adaptation from low-tolerance to high-tolerance}

Comparison of $\mathrm{X}_{\mathrm{II}^{-}}-0 \%$ and $\mathrm{X}_{\mathrm{I}}-0 \%$ transcriptomes explained the increased tolerance yet higher ethanol productivity in $\mathrm{X}_{\mathrm{II}}$. Higher ethanol-tolerance generally correlated with lower ethanol-productivity, as $\mathrm{X}_{\mathrm{I}}$ and $\mathrm{X}_{\mathrm{II}}$ produced less ethanol than $\mathrm{X}$ (Additional file $2 \mathrm{~B}$ ), which was due to rewired glycolysis $\left(X_{I}\right.$ and $\left.X_{I I}\right)$, suppressed solvent formation genes $\left(X_{I}\right.$ and $\left.X_{I I}\right)$ and inhibited co-enzyme B biosynthesis $\left(X_{I}\right)$. Surprisingly, $\mathrm{X}_{\mathrm{II}}$ both tolerated and produced higher ethanol than $\mathrm{X}_{\mathrm{I}}$ (Additional file 2B; $p=0.01$ ), suggesting positive coevolution of the two traits under certain circumstances (Additional file 8 and Additional file 14B).

In $\mathrm{X}_{\mathrm{II}}-0 \%$ (vs $\mathrm{X}_{\mathrm{I}}-0 \%$ ), $21.6 \%$ (535) of the genes were upregulated, while $1.3 \%$ (33 genes) downregulated. Upregulation was mostly in three categories. First, solvent formation genes (6.54\%) were induced, which included euts (Teth5141940-1946), de novo $\mathrm{B}_{12}$ biosynthesis (Teth5140299-0320) and butyrate biosynthesis (Teth5140936-0944). These likely underpinned the higher-than- $\mathrm{X}_{\mathrm{I}}$ ethanol-production of $\mathrm{X}_{\mathrm{II}}$.

Second, among the carbon/ion transporters repressed in $\mathrm{X}_{\mathrm{I}}$ and $\mathrm{X}_{\mathrm{II}}(\mathrm{X}-0 \%$ as baseline), 51 genes $(10 \%$ of all upregulated genes) were expressed higher in $X_{I I}$ than $X_{I}$ (e.g., Teth5140323-0326 for cobalt transport in $\mathrm{B}_{12}$ biosynthesis), indicating a lesser degree of inhibition in $\mathrm{X}_{\mathrm{II}}$. Notably, dynamically regulated operon structures were observed in these upregulated carbon transporters between $\mathrm{X}_{\mathrm{I}}$ and $\mathrm{X}_{\mathrm{II}}$, including pentose transport (Teth51401610166) and glucose transport (Teth5140412-0414) (Figure 2 and Additional file 19). In $X_{I}$, genes involved in pentose transport were clustered in a single operon (Additional file 19A), as was the case for glucose transport genes (Additional file 19C). However, in $\mathrm{X}_{\mathrm{II}}$, pentose transport genes were transcribed in three suboperons (Additional file 19B), whereas glucose transport genes formed two suboperons (Additional file 19D). Such dynamic operon structures might be a mechanism to precisely tune the ratios of enzyme-encoding transcripts as an adaptation strategy specific at the high-tolerance phase.

Third, general stress-response (5.2\% of all upregulated genes; $[36,41]$ ) was specifically induced in $\mathrm{X}_{\mathrm{II}^{-}}-0 \%$ (vs $\mathrm{X}_{\mathrm{I}^{-}}$ $0 \%$ ). It included ABC transporters, Hsps (e.g., DnaK, GrpE, and Hsp20), peptidases, CRISPRs-associated (Cas) immunity system, ADI pathway, and oxidoreductases. It also included several genes induced in $X_{I}-2 \%$ but not in $\mathrm{X}_{\mathrm{I}}-0 \%$ (vs $\mathrm{X}-0 \%$; i.e., the "Memory" of $\mathrm{X}_{\mathrm{II}^{-}}-0 \%$ ), such as the TetR regulator in efflux systems and the aldo/ ketoreductase in oxidoreduction (Additional file 12B). Interestingly, Teth5141359-1361, an ABC transporter operon in COG V (defense mechanism) was "dynamic". In $\mathrm{X}_{\mathrm{I}}$, Teth5141359-1361 constituted a single operon (Additional file 19E). However, in $\mathrm{X}_{\mathrm{II}}$, they formed two suboperons, with the first (Teth5141359-1360, encoding 
hypothetical protein and $\mathrm{ABC}$ transporter) up-regulated in $\mathrm{X}_{\mathrm{II}}-0 \%$ (vs $\mathrm{X}_{\mathrm{I}}-0 \%$ ) while the second (Teth5141361, a hypothetical protein) not induced (Additional file 19F), suggesting dynamic operon as a mechanism for genespecific upregulation within an operon.

The distinct stress-response program of $X_{\| I}$ and its link to $X_{I}$ Comparison between $\mathrm{X}_{\mathrm{II}}-6 \%$ and $\mathrm{X}_{\mathrm{II}^{-}}-0 \%$ demonstrated how long-term stress shaped the stress-response program in the high-tolerance phase (Figure $5 \mathrm{C}$ ). In $\mathrm{X}_{\mathrm{II}}-6 \%$, despite the downregulation of 1583 genes, 16 were upregulated (Additional file 16B). (i) One extracytoplasmic function (ECF) subfamily $6^{24}$ locus (Teth5141847-1848; Figure 5C and Additional file 14A) was induced, which encodes RNA polymerase subunits that regulate intracellular responses to various extracellular stimuli [41]. In Bacillus subtilis, this ECF 6 (SigM) was activated under ethanol shock and salt stress [50]. (ii) RND family efflux system operon (Teth5140198-0200) was upregulated, which extrudes ethanol [44]. (iii) The iron-containing adh (Teth5140145-0146) operon and the alcohol catabolism operon (Teth5141785-1787), which convert ethanol into other intermediate metabolites, was expressed higher in $\mathrm{X}_{\mathrm{II}}-6 \%$ than $\mathrm{X}_{\mathrm{II}}-0 \%$. The Teth5141786 activated nucleotide sugar and then Teth5141787 transferred glycosyl from nucleotide sugar to alcohol, forming $\mathrm{C}$-glycoside to reduce the intracellular alcohol concentration. Interestingly, in $\mathrm{X}_{\mathrm{II}}-6 \%$, due to functional correlation, they constituted one operon, instead of two suboperons (Teth51417851786 and Teth5141787) in $\mathrm{X}_{\mathrm{II}}-0 \%$ (Additional file 20), suggesting dynamic operons can be condition-dependent. (iv) Peptidoglycan binding domain-containing protein (Teth5140954) in COG V (defense mechanism) was induced, which can protect cell wall from autolysis.

Comparison between $\mathrm{X}_{\mathrm{II}}-6 \%$ and $\mathrm{X}_{\mathrm{I}}-2 \%$ revealed 72 (3\%) upregulated genes and 725 (29\%) downregulated genes (Figure 2 and Additional file 14A; Part VI of Additional file 7), which are key to the $2 \%$-to- $6 \%$ tolerance improvement. The 72 upregulated genes include, (i) iron-containing adh (Teth5140145-0146) operon, which suggested positive correlation between ethanol conversion and tolerance; (ii) purine metabolism operons (Teth5140517-0525 and Teth5142354-2355), which was also upregulated in X under ethanol shock and thus was a shock-adaptation link (Additional file 14A); (iii) cell wall and membrane biosynthesis genes (Teth5141784-1789, Teth5140797-0799 and Teth5141976); (iv) hsps(including dnaK, dnaJ, grpE and $h r c A$; Teth5142078-2081), which were upregulated under $6 \%$-ethanol stress $\left(\mathrm{X}_{\mathrm{II}}-0 \%\right.$ vs $\mathrm{X}_{\mathrm{I}}-0 \%$; $\mathrm{X}_{\mathrm{II}}-6 \%$ vs $\left.\mathrm{X}_{\mathrm{I}}-2 \%\right)$ but not under shock or $2 \%$-ethanol stress $(\mathrm{X}-0.15 \%$ vs $\mathrm{X}-0 \%$; $\mathrm{X}_{\mathrm{I}}-2 \%$ vs $\mathrm{X}_{\mathrm{I}}-0 \%$ ), suggesting their phase-specific functioning; (v) the $6^{24}$ (Teth5141847) which was also a unique feature of $\mathrm{X}_{\mathrm{II}}$ upon ethanol stress; (vi) ribosome protein genes (Teth5140864-0881), which suggested a potential contribution of translation machineries in $\mathrm{X}_{\mathrm{II}}$ tolerance; (vii) transporter genes including $\mathrm{ABC}$ transporter (Teth51402530254, COG P), $\mathrm{Na}^{+} / \mathrm{H}^{+}$exchanger (Teth5141320, COG P) and cellobiose specific PTS IIA (Teth5140265), which were repressed by ethanol in both $\mathrm{X}_{\mathrm{I}}$ and $\mathrm{X}_{\mathrm{II}}$ (X as baseline) yet the inhibition was alleviated in $\mathrm{X}_{\mathrm{II}}-6 \%$ (vs $\mathrm{X}_{\mathrm{I}}-2 \%$ ), potentially explaining the growth of $\mathrm{X}_{\mathrm{II}}$ but not $\mathrm{X}_{\mathrm{I}}$ under $6 \%$ ethanol.

Thus $\mathrm{X}_{\mathrm{I}}$ and $\mathrm{X}_{\mathrm{II}}$ mobilized linked yet distinct defense mechanisms (Figure 2 and Figure 5). The former included RND efflux system and adh operon, both controlling intracellular ethanol. For the latter, $\mathrm{X}_{\mathrm{I}}$ mobilized TetR presumably to activate efflux pumps for ethanol [43] and ADI pathway to maintain $\mathrm{pH}$ balance [25], whereas $\mathrm{X}_{\mathrm{II}}$ employed $6^{24}$, alcohol metabolism operon and peptidoglycan binding domain-containing protein (Teth5140954).

\section{Exploiting the molecular links between shock response} and adaptation for simultaneous improvement of ethanol tolerance and titer

The higher ethanol titer and higher tolerance in $\mathrm{X}_{\mathrm{II}}$ than $\mathrm{X}_{\mathrm{I}}$ suggested ethanol production level was not necessarily negatively correlated with ethanol tolerance. The unraveled links and distinctions among the stress-response programs in $\mathrm{X}, \mathrm{X}_{\mathrm{I}}$ and $\mathrm{X}_{\mathrm{II}}$ provided rational genetic strategies to engineer the two co-evolving traits.

First, adhs were involved in both ethanol production and tolerance $[4,51]$; however the sheer number and apparent redundancy of this metabolic enzyme (nine such loci/operons in X514) in most bacterial genomes confounded rational engineering. In our microevolution model, an iron-containing adh (Teth5140145) exhibited an unique transcriptional choreography (Figure 6A): upon exposure to ethanol, its transcription was induced (by 2.6 folds) in $X$ and $X_{I}$ and dramatically (by 28.2 folds) induced in $\mathrm{X}_{\mathrm{II}}$, yet was inhibited in $\mathrm{X}_{\mathrm{I}}$ and $\mathrm{X}_{\mathrm{II}}$ (which produced lower ethanol) when grown without ethanol (Additional file 2B). Such a transcriptional pattern was highly distinct from any of the other eight $a d h s$, whose expression were either unaltered ( 8 in $\mathrm{X}, 6$ in $\mathrm{X}_{\mathrm{I}}$ and 2 in $\mathrm{X}_{\mathrm{II}}$ ) or severely inhibited ( 2 in $X_{I}$ and 6 in $X_{I I}$, by 3-48 folds; Figure $6 \mathrm{~A}$ ). Thus Teth5140145 might be a key junction between the co-evolving tolerance and titer. To test this hypothesis, the Teth5140145-0146 locus was cloned into a replicating plasmid pIKM1, and transformed into X. This adhoverexpressing strain $\left(\mathrm{X}_{\text {adh }}\right)$ showed improvement in both titer and tolerance: $\mathrm{X}_{a d h}$ produced $33 \%$ more ethanol than plasmid control strain $\mathrm{X}_{\text {vector }}(p=0.007$; Figure $6 \mathrm{E}$ ); moreover, growth (as measured by $\mathrm{OD}_{600}$; Methods) under $0.25 \%, 0.5 \%$ and $1 \%$ exogenous ethanol were all enhanced, e.g., by 31.8 folds under 1\% (Figure 6D and Additional file $21 \mathrm{~A}-\mathrm{B})$, suggesting greatly improved tolerance. 


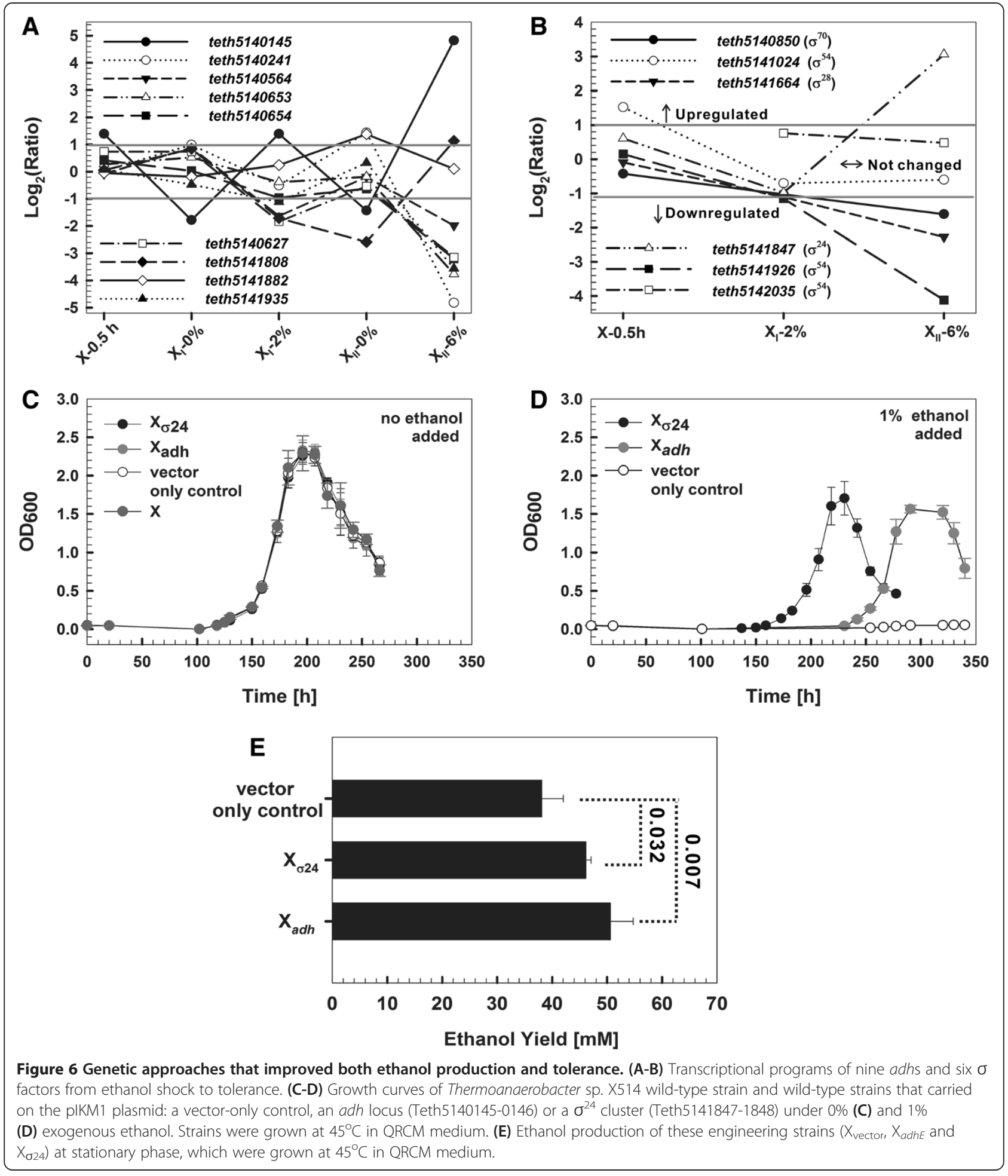

Second, sigma factors are an evolutionarily conserved group of RNA-polymerase subunits that plays regulatory roles [52]. X514 harbors five types of sigma factors: $6^{70}$, $6^{54}, 6^{24}, 6^{28}$ and $6^{29}$. Interestingly, in our microevolution model, $\sigma^{24}$ (Teth5141847) was unique in that it was the only 6 factor up-regulated under $6 \%$ ethanol
(Figure 6B). In E.coli $6^{24}$ was previously recognized as a heat-shock-specific 6 factor [41]. Our engineered strain overexpressing Teth5141847-1848 $\left(\mathrm{X}_{624}\right)$ showed dramatic improvement in growth, e.g., 102-fold enhancement of the control $\left(\mathrm{X}_{\mathrm{vector}}\right.$; as measured by $\left.\mathrm{OD}_{600}\right)$ and $26 \%$ faster than $\mathrm{X}_{a d h}$ under 1\%-ethanol (Figure 6D and 
Additional file $21 \mathrm{~A}-\mathrm{B})$. Furthermore, $\mathrm{X}_{624}$ produced $21 \%$ higher ethanol than $\mathrm{X}_{\mathrm{vector}}(p=0.032$; Figure $6 \mathrm{E})$.

Finally, we found that such two co-evolving traits of ethanol productivity and ethanol tolerance can also be improved by non-genetic approaches (e.g., adaptive evolution and medium supplementation of vitamin $\mathrm{B}_{12}$, Additional file 21C; Part VII of Additional file 7).

\section{Discussion}

Solvent tolerance and productivity are both crucial traits in a CBP scheme of biofuel production from cellulose, where cellulase production, cellulose hydrolysis, pentosehexose co-utilization (one crucial feature of X514 [25]) and solvent production take place in a single bioreactor for maximal energy- and cost-efficiency [4,27,30]. Simultaneous improvement of ethanol tolerance and ethanol titer has been successfully reported in mesophiles (e.g., $S$. cerevisiae and C. acetobutylicum), but not yet in thermophilic bacteria [4,33]. In mesophiles such as $S$. cerevisiae and $C$. acetobutylicum, improvement in both ethanol tolerance and titer were achieved by screening strain libraries overexpressing mutant genes $[14,53]$ or via genomic shuffling [33], yet these approaches required a set of predetermined candidate genes (e.g., two TFs, spt 15 and taf 25 were selected as the targets to generate mutation libraries by gTME [14]) or laborious mutant selection steps $[14,33,53]$, limiting them to a narrow range of hosts (e.g., well studied model organisms). However, as all adaptation started from shock, delineating the temporal characteristics of the adaptation process and testing the mechanistic links between shock and adaptation should serve as essential foundation for modulating genome evolution, including the rational engineering of co-evolving traits.

First, our experimental model revealed the links and distinctions, both global and local, between shock response and adaptation. The "discreteness" of microevolution suggested the feasibility of phase-specific modulation of microevolution, which might carry certain advantages. This was validated by our experiments where overexpressing $6^{24}$ (a gene induced specifically at the high-tolerance phase) improved tolerance more dramatically (102 folds vs 31.8 folds) than overexpressing iron-containing adh (Teth5140145; a gene consistently induced along shock-to-adaptation development). Moreover, "Convergence" raised the possibility of modeling and engineering tolerance based on shock-responses. This hypothesis was validated by our experiment that overexpression of iron-containing adh locus (Teth51401450146), which were the earliest responders in shockresponse, improved tolerance (Figure 6D).

Second, our study unveiled TGPA-specific features of adaptive evolution, compared to mesophiles (e.g., $E$. coli and S. cerevisiae). (i) The higher $\mu_{\mathrm{g}}(0.045)$ in Thermoanaerobacter sp. X514 than that in E. coli
(0.026; [5]) under solvent stress does not support the theoretically postulated much lower $\mu_{\mathrm{g}}$ in thermophiles than in mesophiles [35]. Our finding thus tentatively suggested that TGPAs balance between the deleterious effect of the average mutation and the cost of further reducing mutation rate not by reducing $\mu_{\mathrm{g}}$ but likely by lowering deleteriousness of mutations under stress. (ii) TGPA-specific features of ethanol-shock were unveiled, such as the most vulnerable amino acid metabolism in X514 versus the activated tryptophan biosynthesis in S. cerevisiae, specific activated ADI pathway (e.g., arginine deiminase) yet without activating transcription of Hsps (one key feature of the general shock-response in mesophiles $[8,10])$, and different mechanisms of V-type-ATPase in resisting ethanol (Figure 4B). (iii) TGPA-specific features of ethanol-tolerance were also revealed: distinct mechanisms in membrane metabolism [29,30], specific ADI pathway [38] and its related NAD/NADP octopine (Part III of Additional file 7), and a different solventresponse role of Hsps [11,13,31] (absent induction under either shock or stress; Part V of Additional file 7). Noticeably, Hsps do not seem to play a prominent role in solvent response in thermophiles and their high levels sustaining in thermophiles in the absence of stress was possibly a consequence of long-term evolution under high temperature.

Finally, by elucidating the molecular choreograph underlying an adaptive evolution under solvents, this study demonstrated a strategy to rationally identify the gene targets for engineering the tolerance-productivity relationship. In addition, our experiments showed that simultaneous improvement of ethanol tolerance and productivity is feasible in ethanogenic thermophilic bacteria, and it can be accomplished via genetic routes (e.g., metabolic enzymes (an $a d h$ loci; Teth5140145-0146) or transcriptional regulators (a $6^{24}$ cluster; Teth5141847-1848)). Furthermore, it is conceivable that these novel gene targets identified by our approach can serve as the foundation for rational proteinengineering or mutant protein screening to further improve ethanol tolerance and productivity in this and related thermophiles.

\section{Conclusions}

In adaptive evolution, the molecular links between shockresponse and adaptation remain poorly understood, which hinders rational engineering of solvent tolerance and correlated traits (e.g., productivity). In this study an experimental model was established to track the shock-to-adaptation microevolution in thermophiles. Under ethanol stress, the spontaneous genome mutation rate $\left(\mu_{\mathrm{g}}\right)$ in Thermoanaerobacter, at 0.045 , appears to be equivalent to that in mesophiles (e.g. E.coli) [5]. Shock-response and adaptation were distinct in nature, yet both temporally phased and resilient. In the absence of stimuli, 
transcriptomic states of tolerance mutants resembled their stressed parental strains, while that of high-tolerance mutants resembled the extendedly shocked wild-type. Interestingly, responses to ethanol stress were phase-specific. Upon ethanol shock, X employed fructose-specific PTS, ADI pathway, Adh and a distinct mechanism of V-type ATPase. As an adaptation to ethanol, $\mathrm{X}_{\mathrm{I}}$ mobilized RND efflux system and Adh, whereas $X_{\mathrm{II}}$, which produced higher ethanol than $X_{I}$, employed $6^{24}$, an alcohol catabolism operon and phase-specific Hsps, modulated the operon structures of hexose/pentose transport and reinforced membrane rigidity. Exploiting these links and distinctions between shockresponse and adaptation, we showed ethanol productivity and tolerance can be simultaneously improved by genetic approaches (overexpressing iron-containing adh or $6^{24}$ ).

Therefore, this study revealed thermophilic-bacteria specific features of adaptive evolution and demonstrated a rational strategy to engineer the co-evolution of industrial traits. As improvements of shock-response, stress tolerance and productivity have been crucial and shared aims in industrial applications employing thermophiles [26], our findings should be valuable not just to the production of ethanol but also to a wide variety of biofuels and biochemicals.

\section{Methods}

\section{Adaptive evolution for improved ethanol tolerance}

Thermoanaerobacter sp. X514 was cultured anaerobically in QRCM medium $\left(1.5 \mathrm{~g} / \mathrm{L} \mathrm{KH}_{2} \mathrm{PO}_{4}, 4.2 \mathrm{~g} / \mathrm{L}\right.$ $\mathrm{Na}_{2} \mathrm{HPO}_{4} .12 \mathrm{H}_{2} \mathrm{O}, 3 \mathrm{~g} / \mathrm{L} \mathrm{NaCl}, 0.5 \mathrm{~g} / \mathrm{L} \mathrm{NH} \mathrm{NH}_{4} \mathrm{Cl}, 0.2 \mathrm{~g} / \mathrm{L}$ $\mathrm{MgCl}_{2}, 5 \mathrm{~g} / \mathrm{L}$ yeast extract, $10 \mathrm{~g} / \mathrm{L}$ tryptone, $2 \mathrm{mg} / \mathrm{L}$ resazurin and $0.05 \mathrm{~g} / \mathrm{L}$ and $\mathrm{Cys}-\mathrm{HCl}$ ) supplemented with $50 \mathrm{mM}$ glucose [54] at $60^{\circ} \mathrm{C}$ without shaking. For adaptation evolution under exogenous ethanol, sequential transfer was employed. The wild type strain (X) was initially inoculated into QRCM containing $0.5 \%(\mathrm{v} / \mathrm{v})$ ethanol. When $\mathrm{OD}_{600}$ reached the maximum, cultures were immediately transferred into fresh $0.5 \%$-ethanol medium on a 1:10 volume ratio. The transfer was repeated until $\mathrm{OD}_{600}$ reached a reproducible maximum value, cells were inoculated into $1 \%$-ethanol medium. The cycle was repeated with increasing ethanol concentrations (until 2\% ethanol) for approximately 440 generations over five months. A single clone that grew under $2 \%$ ethanol, $\mathrm{X}_{\mathrm{I}}$, was isolated from the mixed cultures of mutant pools (Xp) (Figure $1 B$ and Additional file 2A). $\mathrm{X}_{\mathrm{I}}$ was mutagenized with ethyl methanesulfonate (EMS) [55] and the mutant pool screened on 6\%-ethanol agar QRCM plate and subsequently in liquid QRCM (Figure $1 \mathrm{~B}$ and Additional file $2 \mathrm{~A})$. One clone that grew the fastest in liquid QRCM (termed $\mathrm{X}_{\mathrm{II}}$ ) was isolated. Further experiments confirmed that the ethanol tolerance phenotypes of both $\mathrm{X}_{\mathrm{I}}$ and $\mathrm{X}_{\mathrm{II}}$ were inheritable and stable after culturing for at least 60 generations in ethanol-free medium. $\mathrm{OD}_{600}$ improvement was measured by $\mathrm{OD}_{600}$ of the treatment divided by that of the control when the former reached the maximum.

In summary, $\mathrm{X}$ was not exposed a priori to exogenous ethanol and thus represented a phase of "ethanol sensitivity", where growth was inhibited at defined medium in the mid-log with $0.15 \%$ exogenous ethanol (Additional file $1 \mathrm{~A}) . \mathrm{X}_{\mathrm{I}}$ represented the "low-tolerance" phase while $\mathrm{X}_{\mathrm{II}}$ represented the "high-tolerance" phase, as they tolerated $2 \%$ and $6 \%$ ethanol respectively.

\section{Ethanol shock}

To determine the effect of ethanol on $\mathrm{X}$ growth, a wide range of ethanol concentrations $(0.1 \% \sim 2 \%(\mathrm{v} / \mathrm{v}))$ were tested first (data not shown) and then narrowed down to $0.15 \%(\mathrm{v} / \mathrm{v})$ that caused stress but not significant cell death in defined medium $\left(0.08 \mathrm{~g} / \mathrm{L} \mathrm{CaCl}{ }_{2} \cdot 2 \mathrm{H}_{2} \mathrm{O}, 1.0 \mathrm{~g} / \mathrm{L}\right.$ $\mathrm{NH}_{4} \mathrm{Cl}, 0.2 \mathrm{~g} / \mathrm{L} \quad \mathrm{MgCl}_{2} \cdot 6 \mathrm{H}_{2} \mathrm{O}, 1.0 \mathrm{~g} / \mathrm{L} \mathrm{NaCl}, 7.2 \mathrm{~g} / \mathrm{L}$ HEPES, $2.52 \mathrm{~g} / \mathrm{L} \mathrm{NaHCO}_{3}, 0.05 \mathrm{~g} / \mathrm{L}$ L-cysteine-HCl,

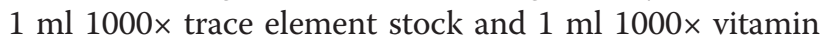
stock solution) supplemented with $50 \mathrm{mM}$ glucose $[8,25]$ (Additional file 1A). Thus all subsequent ethanol shock assays were conducted at $0.15 \%(\mathrm{v} / \mathrm{v})$ ethanol in defined medium. In triplicate experiments, ethanol was added to the medium for an exogenous concentration of $0.15 \%$ when $\mathrm{X}$ was grown to exponential phase $\left(\mathrm{OD}_{600}=0.12\right)$. An identical volume of water was added to the controls. After $0.5 \mathrm{~h}, 1 \mathrm{~h}, 2 \mathrm{~h}$ and $4 \mathrm{~h}$ of the addition, cells were harvested and cell pellets frozen immediately in liquid $\mathrm{N}_{2}$ and stored at $-80^{\circ} \mathrm{C}$ prior to RNA extraction for microarray experiments.

\section{Ethanol stress}

The mutant strains were grown at $60^{\circ} \mathrm{C}$ in triplicates in defined medium without ethanol $\left(\mathrm{X}_{\mathrm{I}}\right.$ and $\left.\mathrm{X}_{\mathrm{II}}\right)$, with $2 \%$ ethanol $\left(\mathrm{X}_{\mathrm{I}}\right)$ and with $6 \%$ ethanol $\left(\mathrm{X}_{\mathrm{II}}\right)$ respectively. Cells were harvested at mid-exponential phase followed by microarray experiments as described above. For sugars and metabolites quantification, samples were harvested at stationary phase and analyzed using HPLC [25].

\section{Effects of exogenous vitamin $B_{12}$ on ethanol production for Thermoanaerobacter sp. X514 (X, $X_{1}$ and $\left.X_{I I}\right)$}

To test the effect of co-enzyme $B_{12}$ on ethanol productivity, $0 \times, 1 \times, 2 \times$ to $4 \times B_{12}(0.1 \mathrm{mg} / \mathrm{L}$ as $1 \times)$ was added to the defined medium at $60^{\circ} \mathrm{C}$, followed by inoculation of $\mathrm{X}, \mathrm{X}_{\mathrm{I}}$ and $\mathrm{X}_{\mathrm{II}}$, respectively. Ethanol concentration at stationary phase was measured by HPLC [25].

\section{Microarray experiments and data analysis}

Thermoanaerobacter sp. X514 whole-genome oligonucleotide (70mer) microarray [25] was used in this study. Total cellular RNA and genomic DNA were isolated, labeled and then hybridization and data analysis performed as previously described [25]. For ethanol shock, the trasncriptomes 
of X-0.15\% (X cells cultured at defined medium with $0.15 \%$ exogenous ethanol; Additional file 1A) were compared to that of $\mathrm{X}-0 \%$ (X cells cultured without exogenous ethanol). On the other hand, the transcriptomes of $\mathrm{X}_{\mathrm{I}}$ under $0 \%$ and $2 \%$ ethanol and those of $\mathrm{X}_{\mathrm{II}}$ under $0 \%$ and $6 \%$ ethanol were compared respectively to reveal the mechanism of ethanol adaptation. Cutoffs of mean $\left|\log _{2}\left(R_{\text {treatment }} / R_{\text {control }}\right)\right| \geq 1.0$ and $\mid Z$ score $\mid \geq 2.0$ were used to determine significant expression changes $[25,34]$. The totally 39 microarray datasets were deposited as NCBI GEOGSE32630.

\section{Gene co-expression networks for shock response}

Twelve microarray datasets for the ethanol shock (three replicates for each of the four time points) and the corresponding twelve control datasets were respectively generated and used via co-expression analysis to construct the two co-expression networks with random matrix theory approach [25,56] (Additional file 6). For each spot on microarray, a normalized $\mathrm{Cy} 5 / \mathrm{Cy} 3$ ratio $(\mathrm{R})$ was calculated and its logarithmic transformation performed. Pearson correlation coefficient cut-off was 0.98 (both for $\mathrm{ES}^{+}$and $\mathrm{ES}^{-}$) between each gene-pair. The modules were separated by fast greedy modularity optimization [56]. Hierarchical clustering analysis was performed using K-Means/KMedians Clustering to identify expression patterns each shared by a sub-set of genes throughout the duration of the ethanol shock response (Additional file 9).

\section{Hierarchical clustering analysis of transcriptomes}

Hierarchical clustering analysis (support tress) among the nine transcriptional profiles from shock (X-0.15\% at each of the four time points of $0.5 \mathrm{~h}, 1 \mathrm{~h}, 2 \mathrm{~h}$ and $4 \mathrm{~h}$ ) to adaptation $\left(\mathrm{X}_{\mathrm{I}}-0 \%, \mathrm{X}_{\mathrm{I}}-2 \%, \mathrm{X}_{\mathrm{II}}-0 \%, \mathrm{X}_{\mathrm{II}}-6 \%\right.$, each in triplicates) was performed with TM4 software [57] based on Pearson Correlation. Similarly, the clustering analysis among the eight "relative" transcriptomic changes (using genes with more than 2 fold changes) from shock (X$0.15 \%$ vs $\mathrm{X}-0 \%$ at each of the four time points of $0.5 \mathrm{~h}$, $1 \mathrm{~h}, 2 \mathrm{~h}$ and $4 \mathrm{~h})$ to adaptation $\left(\mathrm{X}_{\mathrm{I}}-0 \%\right.$ vs $\mathrm{X}-0 \%, \mathrm{X}_{\mathrm{I}}-2 \%$ vs $\mathrm{X}_{\mathrm{I}}-0 \%, \mathrm{X}_{\mathrm{II}}-0 \%$ vs $\mathrm{X}-0 \%, \mathrm{X}_{\mathrm{II}}-6 \%$ vs $\mathrm{X}_{\mathrm{II}}-0 \%$, each in triplicates) was performed via the same method.

\section{RNA-Seq for detecting structural variation of transcripts}

For $\mathrm{X}, \mathrm{X}_{\mathrm{I}}$ and $\mathrm{X}_{\mathrm{II}}, 10 \mu \mathrm{g}$ of the same total RNA samples from ethanol stress and normal growth condition (in the absence of ethanol) in triplicates were used for highthroughput RNA-Sequencing. The cDNA libraries (X$0 \%, X_{I}-0 \%, X_{I}-2 \%, X_{I I}-0 \%$ and $\left.X_{I I}-6 \%\right)$ were constructed as previously described [58]. The samples were quantified spectrophotometrically using Nanodrop (Thermo, USA) and sequenced in a Solexa GA-IIx (Illumina, USA). The raw $2 \times 100 \mathrm{bp}$ reads, after quality screening, were mapped to the Thermoanaerobacter sp. X514 reference genome sequence [34] (NCBI accession number:
NC_010320.1) using SOAP [59], allowing for 2nt mismatches. These uniquely mapped sequences were further analyzed to calculate transcript coverage map based on the number of uniquely mapped reads per locus. The RNA-Seq datasets were deposited as NCBI accession number SRA046273.1.

\section{Detection of dynamic operon structures}

Genes within an operon were defined based on continuous read coverage, transcript abundance and detection of pair-end reads among these genes in all of the triplicates. A new operon was defined when two requirements were met in each of the triplicate samples: 1) uniquely mapped pair-end reads were detected; 2) a significant change (greater than two-fold) of read coverage was found between genes in one predicted polycistron.

\section{Genome-wide mutation profiling via whole-genome sequencing}

Genomic DNA of X, Xp, $\mathrm{X}_{\mathrm{I}}$ and $\mathrm{X}_{\mathrm{II}}$ were isolated [25] and then shot gun libraries constructed [58] and sequenced on Solexa GA-IIx (Illumina, USA). MAQ [60], Samtools [61] and GATK [62] were used respectively for read alignment to Thermoanaerobacter sp. X514 reference genome (NC_010320.1; [34]) and SNP calling. Those predicted SNPs shared among the three were then manually examined (Additional file 10) and then validated by sequencing a selected set of mutated genes (five in $\mathrm{X}_{\mathrm{I}}$ and six in $\mathrm{X}_{\mathrm{II}}$ ) using gene-specific primer pairs (Additional file 12A). For each gene, ten clones were randomly picked for Sanger sequencing (Invitrogen, USA). The results were consistent with Solexa sequencing (Additional file 12B). All sequences were deposited under NCBI accession number SRA046273.1.

\section{Plasmid and strain construction}

A $3.4 \mathrm{~kb}$ PCR fragment encoding the $3.1 \mathrm{~kb}$ ironcontaining adh and NADH oxidase gene (Teth51401450146) flanked by its $197 \mathrm{bp}$ promoter and $48 \mathrm{bp}$ transcription terminator region was amplified from the genome of Thermoanaerobacter sp. X514 and subsequently ligated into plasmid pIKM1 [54] through EcoRI and BamHI. Similarly, $1.7 \mathrm{~kb}$ PCR fragment encoding

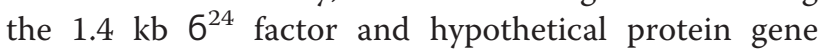
(Teth5141847-1848) with its 245 bp promoter and 80 bp transcription terminator region was amplified and subcloned into pIKM1 through XbaI and KpnI. Plasmids were then transformed into Thermoanaerobacter sp. X514 wild type strain (X) based on our published protocol [54]. These plasmid containing strains were cultured in QRCM medium at $45^{\circ} \mathrm{C}$ and cell samples were collected at stationary phase for ethanol titer quantification. 
Homology modeling of the structure of mutant proteins For the X514 wild-type and mutant protein sequences (DeoR family transcriptional factor (Teth5141305) and the ADH domain of AdhE (Teth5140627), queries were aligned to structural templates in PDB using NCBI protein BLAST. The homology models of 3D protein structures that included cofactors and ligands were constructed via MODELLER [63].

\section{Additional files}

Additional file 1: Impact of ethanol shock on the growth and gene expression of Thermoanaerobacter sp. X514 (wild type). A) Ethanol of different concentrations was added to cultures in early-mid exponential phase, and growth was subsequently monitored as $\mathrm{OD}_{600}$. Data were averaged from triplicate cultures, with error bars indicating standard deviations. B) Numbers of the significantly up- or down-regulated genes under each condition. Each column represented the number of genes with significant expression changes $\left(\left|\log _{2} R\right| \geq 1\right.$ and $\mid Z$ score $\left.|\geq 2|\right)$ at the corresponding time points.

Additional file 2: Thermoanaerobic growth conditions and glucose fermentation by Thermoanaerobacter sp. X514 wild type and ethanol tolerant mutants. A) Growth curves of $X_{1} X_{1}$ and $X_{\|}$in defined medium with or without exogenous ethanol. B) Substrate utilization and product profiles of $X_{1} X_{I}$ and $X_{\|}$in defined medium.

Additional file 3: Scanning electron microscopy images of the Thermoanaerobacter sp. X514 wild-type and mutants.

Additional file 4: Statistical analysis of the mutations in $X, X p, X$ and $X_{11}$ Genomes.

Additional file 5: Functional patterns of significantly expressionaltered Genes in $X_{1}(A)$ and $X_{I I}(B)$ under ethanol-supplemented and ethanol-free media respectively. Proportions of differentially expressed genes under each COG among the total number of differentially expressed genes were indicated.

Additional file 6: Gene co-expression networks of Thermoanaerobacter under ethanol shock and normal growth condition. A) A global view of the network under normal growth condition (ES). B) A global view of the network under ethanol shock $\left(\mathrm{ES}^{+}\right)$. Number in bracket represents the number of genes in each module. Each node represented a gene, which was color-coded using its predicted COG-based functional classification (http://www.ncbi.nlm.nih. gov/nuccore/NC_010320; NC_010320.1).

Additional file 7: Supplemental Materials.

Additional file 8: The List of differentially expressed genes by $X$ for at least one time points in each cluster under $0.15 \%(\mathrm{v} / \mathrm{v})$ ethanol shock.

Additional file 9: Clustering results of gene-expression patterns in the $\mathrm{X}$ under ethanol shock. Ten clusters were obtained by the $\mathrm{HCL}$ method (TM4 software). Each panel displayed the expression dynamics of one such cluster. The horizontal axis indicated the time points of the data, and vertical axis was log (base 2) expression ratio.

Additional file 10: Genomic mutations shared among the three mutations-lists identified by MAQ, Samtools and GATK respectively. A) $X_{\text {; }}$ ) $\left.X p ; C\right) X_{1}$; D) $X_{\| 1}$

Additional file 11: The SNPs in non-coding region. Red: the mutated base; base in brackets: reference base at mutated point; dash: single base deletion. Promoters were predicted by Berkeley Drosophila Genome Project (prokaryote organism; http://www.fruitfly.org/seq_tools/promoter. html).

Additional file 12: Experimental validation of SNPs in $X_{1}$ and $X_{11}$. A) The primer sequences used for PCR and then Sanger sequencing. B) The SNPs validated by Sanger sequencing.
Additional file 13: Priori ethanol stress rewired cellular networks $\left(X_{1}\right.$ and $\left.X_{11}\right)$. Key transport, metabolic and regulatory genes and pathways were illustrated. OD: NAD/NADP octopine dehydrogenase; FITP: ferrous iron transport protein B. Other abbreviations were as in Figure 5.

Additional file 14: Developmental model of solvent-tolerance traits in thermopiles. A) Model of cellular responses upon environmental stimuli: the transition from shock response (wild type) to low-tolerance $\left(X_{1}\right)$ and eventually to high-tolerance $\left(X_{\mid l}\right)$. B) Model of the cellular states after a priori long-term exposure to exogenous ethanol. Boxes represented genes/pathways, whereas box size indicated the number of differentially expressed genes in the pathway. Differential-expression ratios $\left(\log _{2} R\right)$ for the genes/pathways were represented by colors. Asterisks indicated non-synonymous mutated genes in the pathways or the SNPs in predicted promoters of genes. Tra (P): ABC transporter related in COG P; MM: membrane metabolism; AAM: amino acid metabolism; LFA: long-chain fatty acid.

Additional file 15: Differentially expressed genes in mutant. A) $X_{1}$ under normal growth condition $\left(\mathrm{X}_{1}-0 \%\right)$. B) $\mathrm{X}_{\|}$under normal growth condition $\left(\mathrm{X}_{11}-0 \%\right)$.

Additional file 16: Differentially expressed genes in mutants under ethanol stress. A) $X_{1}$ under $2 \%$ ethanol $\left(X_{1}-2 \%\right)$. B) $X_{\|}$under $6 \%$ ethanol $\left(\mathrm{X}_{11}-6 \%\right)$.

Additional file 17: Homology models of the mutant protein structures DeoR (A) and AdhE (B) in Thermoanaerobacter sp. X514. Mutation sites, cofactors and ligands were respectively labeled.

Additional file 18: The Dynamic operons between $X$ and $X_{\text {II }}$ (Teth5140597-0601). Gray and black areas respectively represented the coverage of mRNA in $X$ and $X_{\|}$in ethanol-free media. The scale with the relative score indicated, for each library and at a given nucleotide (among the three biological replicates), the mean number of uniquely mapped reads normalized to the total number of such reads.

Additional file 19: The Dynamic operons between $X_{1}$ and $X_{11}$ in the absence of ethanol. A-B) Teth5140161-0166; C-D) Teth5140412-0414; E-F) Teth5141359-1361. The scale was as in Additional file 18.

Additional file 20: The Dynamic operon between $\mathrm{X}_{11}-0 \%$ and $\mathrm{X}_{11}-6 \%$ (Teth5141785-1787). The scale was as in Additional file 18.

Additional file 21: Genetic and non-genetic approaches that improved both ethanol production and tolerance. A-B) Growth curves of Thermoanaerobacter sp. X514 wild type strains that carried different plasmids (a vector-only control, an adh cluster (Teth51401450146) or a $\sigma^{24}$ cluster (Teth5141847-1848)). Strains were grown at $45^{\circ} \mathrm{C}$ in QRCM medium with $0.25 \%$ and $0.5 \%$ added ethanol respectively. C) Fermentation experiments testing effects of vitamin $B_{12}$ on ethanol production of tolerant mutants in defined medium at $60^{\circ} \mathrm{C}$. Vitamin $B_{12}$ concentrations in defined medium were indicated on $\mathrm{x}$-axis. The means (and standard deviation) for the three biological replicates were shown for each sample. Differences in means were evaluated using one-tailed paired $t$-test (those with $p<0.05$ were shown).

\section{Abbreviations}

AK: Acetate kinase; Aldh (Teth5141942): Aldehyde dehydrogenase; Adh (Teth5140145): Alcohol dehydrogenase; ADI pathway (Teth51404830485): Arginine deiminase pathway; AdhE (Teth5140627): Bifunctional aldehyde/alcohol dehydrogenase; Cas immunity system: CRISPRs-associated immunity system; Euts (Teth5141943-1946): Ethanolamine utilization protein genes; $X_{11}: 6 \%$ ethanol tolerant mutant; EMS: Ethyl methanesulfonate; $\mu_{\mathrm{g}}$ : Genome mutation rate; Hsps: Heat shock proteins; ipmdh: 3 isopropylmalate dehydrogenase; Ldh (Teth5140216): Lactate dehydrogenase; $X_{\text {: }}$ One single colony from Xp; Oad (Teth5141582): Oxaloacetate decarboxylase; PTS: Phosphotransferase system; Xp: Pool of 2\% ethanol tolerant spontaneous mutants of Thermoanaerobacter sp. X514; MreC (Teth5142133): Rod shape-determining protein; RodA (Teth5142127): Rod shape-determining protein; RND efflux system: Resistance-nodulation-cell division family efflux transporter; TetR: Tetracycline repressor family transcription factor; TGPAs: Thermophilic gram-positive anaerobes; $X$ : Wildtype Thermoanaerobacter sp. X514. 


\section{Competing interests}

The authors declare that they have no conflict of interest.

\section{Authors' contributions}

$\mathrm{LL}$ and JX conceived and designed the study. LL, YJ, HS, XZ, LT and KW performed experiments. JZ and ZH assisted microarray experiment design and analysis. QT constructed co-expression gene networks. RH and QZ assisted RNA-Seq data analysis. YL and QC assisted protein structure modeling. JX and LL analyzed all data and wrote the paper. All authors read and approved the final manuscript.

\section{Acknowledgements}

This work was supported by Grants 2011CB707404 and 2011BAD22B02 from MoST of China, 91231205 and 30870572 from NNSF of China, JQ200822 and BS2009SW022 from NSF of Shandong and KSCX1-YW-11C2 from CAS, and by the US NSF EPSCOR Grant EPS-0814361 and the Oklahoma Bioenergy Center.

\section{Author details}

${ }^{1}$ BioEnergy Genome Center, CAS Key Laboratory of Biofuels and Shandong Key Laboratory of Energy Genetics, Qingdao Institute of Bioenergy and Bioprocess Technology, Chinese Academy of Sciences, Qingdao, Shandong, P. R. China. Institute for Environmental Genomics, and Department of Microbiology and Plant Biology, University of Oklahoma, Norman, OK, USA.

Received: 29 May 2013 Accepted: 17 July 2013

Published: 22 July 2013

\section{References}

1. Barrick JE, Yu DS, Yoon SH, Jeong H, Oh TK, Schneider D, Lenski RE, Kim JF: Genome evolution and adaptation in a long-term experiment with Escherichia coli. Nature 2009, 461:1243-1247.

2. Wiegel J, Adams MWW: Thermophiles: The Keys to the Molecular Evolution and the Origin of Life. Philadelphia: Taylor \& Francis e-Library; 2003.

3. Lenski RE, Ofria C, Pennock RT, Adami C: The evolutionary origin of complex features. Nature 2003, 423:139-144.

4. Brown SD, Guss AM, Karpinets TV, Parks JM, Smolin N, Yang S, Land ML, Klingeman DM, Bhandiwad A, Rodriguez M Jr, et al: Mutant alcohol dehydrogenase leads to improved ethanol tolerance in Clostridium thermocellum. Proc Natl Acad Sci USA 2011, 108:13752-13757.

5. Minty JJ, Lesnefsky AA, Lin F, Chen Y, Zaroff TA, Veloso AB, Xie B, McConnell CA, Ward RJ, Schwartz DR, et al: Evolution combined with genomic study elucidates genetic bases of isobutanol tolerance in Escherichia coli. Microb Cell Fact 2011, 10:18

6. Atsumi S, Wu TY, Machado IM, Huang WC, Chen PY, Pellegrini M, Liao JC: Evolution, genomic analysis, and reconstruction of isobutanol tolerance in Escherichia coli. Mol Syst Biol 2010, 6:449.

7. Blount ZD, Barrick JE, Davidson CJ, Lenski RE: Genomic analysis of a key innovation in an experimental Escherichia coli population. Nature 2012, 489:513-518

8. Rutherford BJ, Dahl RH, Price RE, Szmidt HL, Benke PI, Mukhopadhyay A, Keasling JD: Functional genomic study of exogenous n-butanol stress in Escherichia coli. Appl Environ Microbiol 2010, 76:1935-1945.

9. Brynildsen MP, Liao JC: An integrated network approach identifies the isobutanol response network of Escherichia coli. Mol Syst Biol 2009, 5:277.

10. Stanley D, Bandara A, Fraser S, Chambers PJ, Stanley GA: The ethanol stress response and ethanol tolerance of Saccharomyces cerevisiae. J Appl Microbiol 2010, 109:13-24.

11. Ma M, Liu ZL: Mechanisms of ethanol tolerance in Saccharomyces cerevisiae. Appl Microbiol Biotechnol 2010, 87:829-845

12. Tomas CA, Welker NE, Papoutsakis ET: Overexpression of groESL in Clostridium acetobutylicum results in increased solvent production and tolerance, prolonged metabolism, and changes in the cell's transcriptional program. Appl Environ Microbiol 2003, 69:4951-4965

13. Tomas CA, Beamish J, Papoutsakis ET: Transcriptional analysis of butanol stress and tolerance in Clostridium acetobutylicum. J Bacteriol 2004, 186:2006-2018.

14. Alper H, Moxley J, Nevoigt E, Fink GR, Stephanopoulos G: Engineering yeast transcription machinery for improved ethanol tolerance and production. science 2006, 314:1565-1568.
15. Gill RT, Wildt S, Yang YT, Ziesman S, Stephanopoulos G: Genome-wide screening for trait conferring genes using DNA microarrays. Proc Nat Acad Sci USA 2002, 99:7033-7038

16. Warnecke TE, Lynch MD, Karimpour-Fard A, Lipscomb ML, Handke P, Mills T, Ramey CJ, Hoang T, Gill RT: Rapid dissection of a complex phenotype through genomic-scale mapping of fitness altering genes. Metab Eng 2010, 12:241-250.

17. Winkler J, Kao KC: Harnessing recombination to speed adaptive evolution in Escherichia coli. Metab Eng 2012, 14:487-495.

18. Kao KC, Sherlock G: Molecular characterization of clonal interference during adaptive evolution in asexual populations of Saccharomyces cerevisiae. Nat Genet 2008, 40:1499-1504.

19. Reyes LH, Almario MP, Kao KC: Genomic library screens for genes involved in n-butanol tolerance in Escherichia coli. PLoS One 2011, 6:e17678.

20. Woodruff LB, Gill RT: Engineering genomes in multiplex. Curr Opin Biotechnol 2011, 22:576-583.

21. Borden JR, Papoutsakis ET: Dynamics of genomic-library enrichment and identification of solvent tolerance genes for Clostridium acetobutylicum. Appl Environ Microbiol 2007, 73:3061-3068.

22. Nicolaou SA, Gaida SM, Papoutsakis ET: A comparative view of metabolite and substrate stress and tolerance in microbial bioprocessing: From biofuels and chemicals, to biocatalysis and bioremediation. Metab Eng 2010, 12:307-331.

23. Warner JR, Reeder PJ, Karimpour-Fard A, Woodruff LBA, Gill RT: Rapid profiling of a microbial genome using mixtures of barcoded oligonucleotides. Nat Biotech 2010, 28:856-862.

24. Brock TD (Ed): In thermophiles: general, molecular and applied microbiology. New York: John Wiley \& Sons; 1986

25. Lin L, Song H, Tu Q, Qin Y, Zhou A, Liu W, He Z, Zhou J, Xu J: The Thermoanaerobacter glycobiome reveals mechanisms of pentose and hexose co-utilization in bacteria. PLoS Genet 2011, 7:e1002318.

26. $L$ in $L, X u$ J: Dissecting and engineering metabolic and regulatory networks of thermophilic bacteria for biofuel production. Biotechnol Adv 2013. doi.org/10.1016/j.biotechadv.2013.03.003

27. Taylor MP, Eley KL, Martin S, Tuffin MI, Burton SG, Cowan DA: Thermophilic ethanologenesis: future prospects for second-generation bioethanol production. Trends Biotechnol 2009, 27:398-405.

28. Shaw AJ, Podkaminer KK, Desai SG, Bardsley JS, Rogers SR, Thorne PG Hogsett DA, Lynd LR: Metabolic engineering of a thermophilic bacterium to produce ethanol at high yield. Proc Natl Acad Sci USA 2008, 105:13769-13774

29. Taylor M, Tuffin M, Burton S, Eley K, Cowan D: Microbial responses to solvent and alcohol stress. Biotechnol J 2008, 3:1388-1397.

30. Timmons MD, Knutson BL, Nokes SE, Strobel HJ, Lynn BC: Analysis of composition and structure of Clostridium thermocellum membranes from wild-type and ethanol-adapted strains. Appl Microbiol Biotechnol 2009, 82:929-939.

31. Goodarzi H, Bennett BD, Amini S, Reaves ML, Hottes AK, Rabinowitz JD, Tavazoie S: Regulatory and metabolic rewiring during laboratory evolution of ethanol tolerance in E. coli. Mol Syst Biol 2010, 6:378.

32. Bond-Watts BB, Bellerose RJ, Chang MCY: Enzyme mechanism as a kinetic control element for designing synthetic biofuel pathways. Nat Chem Biol 2011, 7:222-227.

33. Mao S, Luo Y, Zhang T, Li J, Bao G, Zhu Y, Chen Z, Zhang Y, Li Y, Ma Y: Proteome reference map and comparative proteomic analysis between a wild type Clostridium acetobutylicum DSM 1731 and its mutant with enhanced butanol tolerance and butanol yield. J Proteome Res 2010, 9:3046-3061.

34. Hemme CL, Fields MW, He Q, Deng Y, Lin L, Tu Q, Mouttaki H, Zhou A, Feng $X$, Zuo $Z$, et al: Correlation of genomic and physiological traits of thermoanaerobacter species with biofuel yields. Appl Environ Microbiol 2011, 77:7998-8008.

35. Drake JW: Avoiding dangerous missense: thermophiles display especially low mutation rates. PLOS Genet 2009, 5:e1000520.

36. Moat AG, Foster JW, Spector MP: Microbial stress responses, Microbial Physiology. 4th edition. New York: Wiley-Liss, Inc; 2002.

37. Penrod JT, Roth JR: Conserving a volatile metabolite: a role for carboxysome-like organelles in Salmonella enterica. J Bacteriol 2006 188:2865-2874

38. Angelis MD, Mariotti L, Rossi J, Servili M, Fox PF, Rollan G, Gobbetti M: Arginine catabolism by sourdough lactic acid bacteria: Purification and 
characterization of the arginine deiminase pathway enzymes from Lactobacillus sanfranciscensis CB1. Appl Environ Microbiol 2002, 68:6193-6201

39. Bateman $A$, Bycroft M: The structure of a LysM domain from E. coli membrane-bound lytic murein transglycosylase D (MItD). J Mol Biol 2000, 299:1113-1119.

40. Turner PC, Mclennan AG, Bates AD, White MRH: Instant Notes in Molecular Biology. 3rd edition. Liverpool, UK: University of Liverpool; 2001.

41. Boor KJ: Bacterial stress responses: what doesn't kill them can make then stronger. PLOS Biol 2006, 4:e23.

42. Seibel BA, Thuesen EV, Childress JJ: Light-limitation on predator-prey interactions: consequences for metabolism and locomotion of deep-sea cephalopods. Biol Bull 2000, 198:284-298.

43. Hillerich B, Westpheling J: A new TetR family transcriptional regulator required for morphogenesis in Streptomyces coelicolor. J Bacteriol 2008 190:61-67.

44. Dunlop MJ: Engineering microbes for tolerance to next-generation biofuels. Biotechnol Biofuels 2011, 4:32.

45. Roberts IS: The biochemistry and genetics of capsular polysaccharide production in bacteria. Annu Rev Microbiol 1996, 50:285-315.

46. Okochi M, Kurimoto M, Shimizu K, Honda H: Increase of organic solvent tolerance by overexpression of manXYZ in Escherichia coli. Appl Microbiol Biotechnol 2007, 73:1394-1399.

47. Cabeen MT, Jacobs-Wagner C: Bacterial cell shape. Nat Rev Microbiol 2005 3:601-610.

48. Schujman GE, Paoletti L, Grossman AD, de Mendoza D: FapR, a bacterial transcription factor involved in global regulation of membrane lipid biosynthesis. Dev Cell 2003, 4:663-672.

49. Alsaker KV, Spitzer TR, Papoutsakis ET: Transcriptional analysis of spo0A overexpression in Clostridium acetobutylicum and its effect on the cell's response to butanol stress. J Bacterio/ 2004, 186:1959-1971.

50. Horsburgh MJ, Moir A: Sigma M, an ECF RNA polymerase sigma factor of Bacillus subtilis 168 , is essential for growth and survival in high concentrations of salt. Mol Microbiol 1999, 32:41-50

51. Peng $H, W u G$, Shao $W$ : The aldehyde/alcohol dehydrogenase (AdhE) in relation to the ethanol formation in Thermoanaerobacter ethanolicus JW200. Anaerobe 2008, 14:125-127.

52. Vorholt JA, Francez-Charlot A, Frunzke J, Reichen C, Ebneter JZ, Gourion B: Sigma factor mimicry involved in regulation of general stress response. Proc Natl Acad Sci USA 2009, 106:3467-3472.

53. Hong ME, Lee KS, Yu BJ, Sung YJ, Park SM, Koo HM, Kweon DH, Park JC, Jin YS: Identification of gene targets eliciting improved alcohol tolerance in Saccharomyces cerevisiae through inverse metabolic engineering. J Biotechnol 2010, 149:52-59.

54. Lin L, Song H, Ji Y, He Z, Pu Y, Zhou J, Xu J: Ultrasound-mediated DNA transformation in thermophilic Gram-positive anaerobes. PLoS One 2010 5(9):e12582

55. Nieto JJ, Fernandezcastillo R, Megias M, Ruizberraquero F: Ethyl Methanesulfonate Mutagenesis in Extremely Halophilic ArchaebacteriaIsolation of Auxotrophic Mutants of Haloferax-Mediterranei and Haloferax-Gibbonsii. Curr Microbiol 1992, 24:41-47.

56. Zhou J, Deng Y, Luo F, He Z, Tu Q, Zhi X: Functional molecular ecological networks. MBio 2010, 1(4):e00169-00110.

57. Saeed Al, Bhagabati NK, Braisted JC, Liang W, Sharov V, Howe EA, Li J, Thiagarajan M, White JA, Quackenbush J: TM4 microarray software suite. Methods Enzymol 2006, 411:134-193.

58. Camarena L, Bruno V, Euskirchen G, Poggio S, Snyder M: Molecular mechanisms of ethanol-induced pathogenesis revealed by RNAsequencing. PLoS Pathog 2010, 6:e1000834.

59. Li R, Yu C, Li Y, Lam TW, Yiu SM, Kristiansen K, Wang J: SOAP2: an improved ultrafast tool for short read alignment. Bioinformatics 2009, 25:1966-1967

60. Li H, Ruan J, Durbin R: Mapping short DNA sequencing reads and calling variants using mapping quality scores. Genome Res 2008, 18:1851-1858.

61. Li H, Handsaker B, Wysoker A, Fennell T, Ruan J, Homer N, Marth G, Abecasis G, Durbin R: The Sequence alignment/map (SAM) format and SAMtools. Bioinformatics 2009, 25:2078-2079.
62. DePristo MA, Banks E, Poplin R, Garimella KV, Maguire JR, Hartl C, Philippakis $A A$, Angel GD, Rivas MA, Hanna M, et al: A framework for variation discovery and genotyping using next-generation DNA sequencing data. Nat Genet 2011, 43:491-498.

63. Fiser A, Sali A: Modeller: generation and refinement of homology-based protein structure models. Methods Enzymol 2003, 374:461-491.

doi:10.1186/1754-6834-6-103

Cite this article as: Lin et al: Microevolution from shock to adaptation revealed strategies improving ethanol tolerance and production in Thermoanaerobacter. Biotechnology for Biofuels 2013 6:103.

\section{Submit your next manuscript to BioMed Central and take full advantage of:}

- Convenient online submission

- Thorough peer review

- No space constraints or color figure charges

- Immediate publication on acceptance

- Inclusion in PubMed, CAS, Scopus and Google Scholar

- Research which is freely available for redistribution

Submit your manuscript at www.biomedcentral.com/submit
() Biomed Central 